OPEN ACCESS

Edited by:

Paul Croarkin,

Mayo Clinic, United States

Reviewed by: Roberta Ferrucci,

University of Milan, Italy

Thorsten Rudroff,

The University of lowa, United States

Craig David Workman,

The University of lowa, United States

*Correspondence:

Pu Wang

wangpu_03@126.com

Xiaogian Gong

13826380678@139.com

Youliang Wen

wenyouliang1971@163.com

tThese authors have contributed equally to this work and share first

authorship

Received: 24 July 2021 Accepted: 27 September 2021

Published: 28 October 2021

Citation:

Liu X, Liu H, Liu Z, Rao J, Wang J, Wang P, Gong $X$ and Wen $Y$ (2021) Transcranial Direct Current Stimulation for Parkinson's Disease: A Systematic Review and Meta-Analysis. Front. Aging Neurosci. 13:746797. doi: 10.3389/fnagi.2021.746797

\section{Transcranial Direct Current Stimulation for Parkinson's Disease: A Systematic Review and Meta-Analysis}

\author{
Xiang Liu ${ }^{1 \dagger}$, Huiyu Liu 1†, Zicai Liu ${ }^{1,2}$, Jinzhu Rao ${ }^{1}$, Jing Wang ${ }^{1}$, Pu Wang ${ }^{3 *}$, \\ Xiaoqian Gong ${ }^{4 *}$ and Youliang Wen ${ }^{2 *}$
}

\begin{abstract}
${ }^{1}$ Department of Rehabilitation Medicine, Yuebei People's Hospital, Shaoguan, China, ${ }^{2}$ School of Rehabilitation Medicine, Gannan Medical University, Ganzhou, China, ${ }^{3}$ Department of Rehabilitation Medicine, The Seventh Affiliated Hospital, Sun Yat-sen University, Shenzhen, China, ${ }^{4}$ Yuebei People's Hospital, Shaoguan, China
\end{abstract}

Background: Parkinson's disease is a common neurodegenerative disorder with motor and non-motor symptoms. Recently, as adjuvant therapy, transcranial direct current stimulation (tDCS) has been shown to improve the motor and non-motor function of patients with Parkinson's disease (PD). This systematic review aimed to evaluate the existing evidence for the efficacy of tDCS for PD. We included English databases (PubMed, the Cochrane Library, Embase, and Web of Science) and Chinese databases [Wanfang database, China National Knowledge Infrastructure (CNKI), China Science and Technology Journal Database (VIP), and China Biology Medicine (CBM)] without restricting the year of publication. Twenty-one tDCS studies, with a total of 736 participants, were included in the analysis. Two independent researchers extracted the data and characteristics of each study. There was a significant pooled effect size $(-1.29$; 95\% Cl $\left.=-1.60,-0.98 ; p<0.00001 ; P^{2}=0 \%\right)$ in the Unified PD Rating Scale (UPDRS) I and the Montreal cognitive assessment (SMD $=0.87,95 \% \mathrm{Cl}=0.50$ to $\left.1.24 ; p<0.00001 ; I^{2}=0 \%\right)$. The poor effect size was observed in the UPDRS III scores $\left(\mathrm{SMD}=-0.13 ; 95 \% \mathrm{Cl}=-0.64,0.38 ; p=0.61 ; l^{2}=77 \%\right)$, and similar results were observed for the timed up and go (TUG) test, Berg balance scale, and gait assessment. The results of this meta-analysis showed that there was insufficient evidence that tDCS improves the motor function of patients with PD. However, tDCS seemed to improve their cognitive performance. Further multicenter research with a larger sample size is needed. In addition, future research should focus on determining the tDCS parameters that are most beneficial to the functional recovery of patients with PD.

Keywords: transcranial direct current stimulation, Parkinson's disease, meta-analysis, review, motor function, cognitive function 


\section{INTRODUCTION}

Parkinson's disease is a common neurodegenerative disease in the elderly and its characteristic pathological changes are the progressive degeneration of the dopaminergic neurons in the substantia nigra and the significant decrease in the dopamine secretion of the striatum (Berg et al., 2014; Beretta et al., 2020a). Parkinson's disease (PD) is uncommon before 50 years of age in men and women, and the prevalence, morbidity, and death rates associated with this condition increase with age. In addition, men are more susceptible to develop this disease than women, and the incidence is 1.4 times higher than that in women. By the age of 60 , the prevalence rate is $\sim 0.5 \%$, while the prevalence rises to $\sim 3.9 \%$ in elderly individuals between 85 and 89 years of age (Dorsey et al., 2018). In China, the prevalence of PD among people over 65 years of age is $\sim 1.7 \%$ (Zhang et al., 2005). The cardinal symptoms of PD include motor- and non-motor-related features. The motor symptoms include bradykinesia, rigidity, and static tremor, as well as postural and gait disorder (Jankovic, 2008). The common disabled non-motor symptoms in patients with PD mainly include emotional and cognitive disorders (Ransmayr, 2015). These symptoms can lead to dysfunctions such as balance disorders, cognitive impairment, and dysphagia, which reduce the ability for self-care in daily life and may even lead to death, increasing the economic burden on the family and society.

The treatment of dysfunctions in patients with $\mathrm{PD}$ requires comprehensive therapy and multidisciplinary participation, including movement therapy, dopamine replacement therapy, and the combined use of anticholinergic agents and deep brain stimulation (Goodwill et al., 2017). However, the effects of the medication may diminish over time (Jankovic and Stacy, 2007). These may include movement symptoms and fluctuations (Jankovic, 2008) and obsessive behaviors (Raja and Bentivoglio, 2012), as well as an increased risk of developing dementia (Gray et al., 2015). Adaptive deep brain stimulation has shown great potential in the treatment of $\mathrm{PD}$, but its applicability in cognitive and other psychiatric disorders remains uncertain (Beudel and Brown, 2016; Guidetti et al., 2021). Therefore, alternative interventions should be explored.

In recent years, a growing number of researchers have paid more and more attention to the study of non-invasive brain stimulation techniques on the function of $\mathrm{PD}$, such as transcranial direct current stimulation (tDCS). tDCS has two electrodes, an anode, and a cathode, which provide constant direct currents on the scalp. It has been shown to induce changes in the resting membrane potential of the cerebral cortex and change the excitability of neurons (Nonnekes et al., 2014). The anode increases the excitability of the cortical tissues, and the cathode decreases the excitability (Broeder et al., 2015; Lefaucheur et al., 2017), which may induce the release of neurotransmitters and increase the extracellular dopamine levels, as has been demonstrated in animal models (Tanaka et al., 2013). This may facilitate signal transduction in brain tissue. In addition, studies have shown that $\mathrm{tDCS}$ on the cognitive regions of the cerebral cortex could improve cortical excitability, and affect cognitive networks (Miniussi et al., 2013). tDCS has been suggested to improve cognitive ability (Boggio et al., 2006; Doruk et al., 2014; Biundo et al., 2015) and verbal fluency (Pereira et al., 2013), and cerebellar tDCS can activate specific neural networks and strengthen the regulation of behavioral responses associated with emotion-related stimuli (Ruggiero et al., 2021). However, studies have shown that between tDCS and sham intervention, there was no difference in the movement performance, reaction time, and self-assessment mobility in the Unified PD Rating Scale (UPDRS; Benninger et al., 2010).

Although tDCS shows great potential in treating PD, the results of the existing studies on the treatment of $\mathrm{PD}$ with $\mathrm{tDCS}$ were inconsistent, so it is necessary to systematically review the existing studies. This systematic review and meta-analysis aimed to summarize the available evidence to evaluate the clinical efficacy of tDCS in the treatment of PD.

\section{METHODS}

The systematic review and meta-analysis were conducted according to the preferred report items of systematic review and meta-analysis (Page et al., 2021).

\section{Eligibility Criteria Study Types}

Only relevant randomized controlled trials (RCTs) were included to investigate the efficacy of tDCS in PD treatment. Comments, case reports, quasi-RCTs, animal experiments, or non-RCTs were excluded.

\section{Participants}

According to diagnostic criteria (National Collaborating Centre for Chronic, 2006), participants diagnosed with PD were included in this review. There were no restrictions on age, gender, or race.

\section{Intervention}

The studies included tDCS intervention alone or in combination with any other interventions, including sham stimulation, Western medical treatment, or rehabilitation. Except for the tDCS intervention in the experimental trial, the interventions in the experimental and comparison trials are the same.

\section{Outcomes}

The primary outcomes were the motor and non-motor function assessments, including the UPDRS, timed up and go test (TUG), Berg balance scale (BBS), gait assessment, mini-mental state examination (MMSE), Montreal cognitive assessment (MoCA), PD-cognitive rating scale (PD-CRS), and PD Quality of Life Questionnaire-39 (PDQ-39).

\section{Search Strategy}

The search was performed by restricting the language to English and Chinese without restricting the year of publication. Two of the authors (Xiang Liu and Huiyu Liu) created a search strategy, which was approved by all authors. To identify all potentially relevant studies, we searched the following databases: English databases: PubMed, the Cochrane Library, Embase, and Web of Science. Chinese databases: Wanfang database, China National Knowledge Infrastructure (CNKI), China Science 
and Technology Journal Database (VIP), and China Biology Medicine (CBM). All searches were conducted in June 2021 and covered the databases from their inception. The search terms were (a) "Parkinson's" or "Parkinson's disease" or "PD" or "idiopathic Parkinson's disease" or "IPD” or "primary Parkinson's syndrome"; (b) "transcranial direct current stimulation" or "tDCS"; and (c) "randomized controlled trials" or "RCTs" or "controlled clinical trial" or "randomized" or "randomly" or "trial."

\section{Study Selection}

The researchers (Xiang Liu and Huiyu Liu) scanned the title, abstract, and keywords of the articles found in the electronic search and excluded the irrelevant articles. Then, we obtained the full text of the included articles; subsequently, the full text of the potential studies was evaluated to determine their acceptability. All the differences and opinions were resolved through a discussion between the two researchers, and the research was selected according to the inclusion criteria. A third reviewer (Wang $\mathrm{Pu}$ or Youliang Wen) was consulted to resolve differences in data extraction.

\section{Data Extraction}

We prepared a data extraction table that included the authors, publication date, and the characteristics (numbers, gender, age, and PD durations, and others), experimental group, control group, stimulation area, intensity, duration, frequency, and period of treatment, outcomes, and adverse events. It was defined

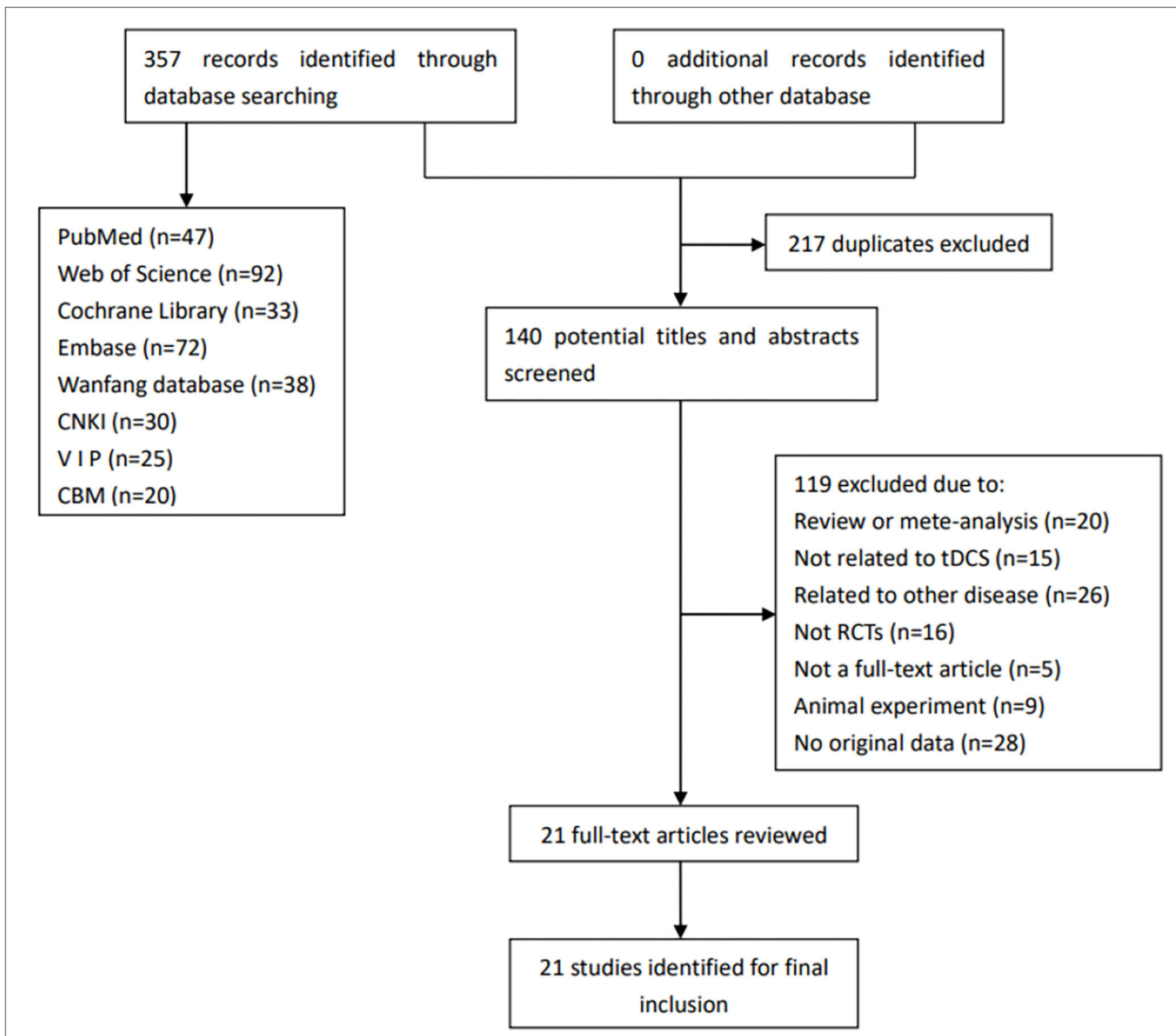

FIGURE 1 | Flow diagram for the selection of the included studies. CBM, China Biology Medicine; CNKI, China National Knowledge Infrastructure; RCTs, randomized controlled trials; tDCS, transcranial direct current stimulation; VIP, China Science and Technology Journal Database. 
that, in the normal use of qualified tDCS, any deleterious event occurring that results in human harm and is not related to the anticipated effects of tDCS.

\section{Assessment of the Risk of Bias in the Included Studies}

The Cochrane bias risk assessment tool (Higgins et al., 2011) was used to assess the methodological quality. Two reviewers (Xiang Liu and Huiyu Liu) independently assessed the risk of bias of each included study according to the following characteristics: random sequence generation, allocation concealment, blinding, completeness of outcome data, selective outcome reporting, and other biases. The risks were classified into three levels: low risk of bias, unclear risk of bias, and high risk of bias. Any difference was resolved through discussions, and if consensus was not reached, the third reviewer ( $\mathrm{Pu}$ Wang or Youliang Wen) was consulted.

\section{Statistical Analyses}

The review Manage 5.3 software (Cochrane, London, United Kingdom) was used to conduct the statistical analyses of the overall and subgroup treatment effects of tDCS intervention in PD. For continuous data, the mean difference (MD) or standardized mean difference (SMD) was used for analysis. The dichotomous data analysis was calculated using the risk ratio (RR), and for both, 95\% CIs was assessed using the $Z$-test.

TABLE 1 | Characteristics of participants included in the studies.

\begin{tabular}{|c|c|c|c|c|c|c|}
\hline References & Total $N$ & Gender (M/F) & Age (year) & PD duration & UPDRS III & LED (mg/d) \\
\hline Wu and Wu (2016) & 100 & $\begin{array}{l}\text { G1:27/23 } \\
\text { G2:26/24 }\end{array}$ & $\begin{array}{c}\text { G1:60.4 } \pm 2.4 \\
\text { G2:59.7 } \pm 2\end{array}$ & NR & $\begin{array}{l}\mathrm{G} 1: 23.9 \pm 6.5 \\
\mathrm{G} 2: 25.1 \pm 7.1\end{array}$ & NR \\
\hline Criminger et al. (2018) & 16 & $12 / 4$ & $68.13 \pm 9.76$ & $8.69 \pm 9.76$ & $23.44 \pm 9.73$ & NR \\
\hline Qiao et al. (2019) & 49 & $\begin{array}{l}\text { G1:11/14 } \\
\text { G2:15/9 }\end{array}$ & $\begin{array}{l}\text { G1:63.00 } \pm 9.20 \\
G 2: 62.04 \pm 9.69\end{array}$ & $\begin{array}{l}\mathrm{G} 1: 5.22 \pm 4.46 \\
\mathrm{G} 2: 6.07 \pm 5.25\end{array}$ & $\begin{array}{l}\text { G1:20.32 } \pm 5.57 \\
G 2: 22.08 \pm 7.51\end{array}$ & $\begin{array}{l}\text { G1:340.64 } \pm 16.78 \\
G 2: 351.63 \pm 128.62\end{array}$ \\
\hline Manenti et al. (2016) & 20 & $\begin{array}{l}\text { G1:4/6 } \\
\text { G2:7/3 }\end{array}$ & $\begin{array}{l}\mathrm{G} 1: 69.0 \pm 6.1 \\
\mathrm{G} 2: 69.1 \pm 5.6\end{array}$ & $\begin{array}{l}\mathrm{G} 1: 7.1 \pm 3.6 \\
\mathrm{G} 2: 7.8 \pm 4.2\end{array}$ & $\begin{array}{l}\mathrm{G} 1: 27.8 \pm 13.9 \\
\mathrm{G} 2: 27.6 \pm 18.9\end{array}$ & $\begin{array}{l}\mathrm{G} 1: 524.6 \pm 179.1 \\
\mathrm{G} 2: 815.7 \pm 590.9\end{array}$ \\
\hline Qiao and Yan (2018) & 30 & $\begin{array}{l}\text { G1:7/8 } \\
\text { G2:9/6 }\end{array}$ & $\begin{array}{c}\text { G1:62.00 } \pm 10.26 \\
G 2: 58.40 \pm 9.13\end{array}$ & $\begin{array}{l}\text { G1:4.03 } \pm 4.94 \\
G 2: 3.51 \pm 2.51\end{array}$ & $\begin{array}{l}\text { G1:18.33 } \pm 4.30 \\
G 2: 19.47 \pm 5.79\end{array}$ & $\begin{array}{l}\text { G1:255.20 } \pm 79.13 \\
G 2: 275.13 \pm 77.47\end{array}$ \\
\hline Li et al. (2018) & 56 & $\begin{array}{l}\text { G1:15/13 } \\
\text { G2:14/14 }\end{array}$ & $\begin{array}{l}\text { G1:64.32 } \pm 5.59 \\
G 2: 64.39 \pm 5.50\end{array}$ & $\begin{array}{l}\mathrm{G} 1: 1.19 \pm 0.57 \\
\mathrm{G} 2: 1.28 \pm 0.56\end{array}$ & $\begin{array}{l}\mathrm{G} 1: 34.5 \pm 13.77 \\
\mathrm{G} 2: 34.6 \pm 12.85\end{array}$ & NR \\
\hline Zhu (2020) & 70 & $\begin{array}{l}\text { G1:24/11 } \\
\text { G2:23/12 }\end{array}$ & $\begin{array}{l}G 1: 77.06 \pm 3.23 \\
G 2: 77.11 \pm 0.25\end{array}$ & $\begin{array}{l}\mathrm{G} 1: 3.62 \pm 2.15 \\
\mathrm{G} 2: 3.95 \pm 2.17\end{array}$ & NR & NR \\
\hline Yang and $\mathrm{He}$ (2017) & 94 & $\begin{array}{l}\text { G1:26/21 } \\
\text { G2:27/20 }\end{array}$ & $\begin{array}{l}\mathrm{G} 1: 62.4 \pm 4.1 \\
\mathrm{G} 2: 62.8 \pm 4.3\end{array}$ & NR & $\begin{array}{l}\mathrm{G} 1: 23.56 \pm 6.39 \\
\mathrm{G} 2: 24.62 \pm 7.62\end{array}$ & NR \\
\hline Wu and Li (2020) & 54 & $\begin{array}{l}\mathrm{G} 1: 16 / 12 \\
\mathrm{G} 2: 14 / 12\end{array}$ & $\begin{array}{l}\text { G1:61.0 } \pm 11.6 \\
G 2: 62.6 \pm 12.2\end{array}$ & $\begin{array}{l}\text { G1:5.8 } \pm 2.6 \\
G 2: 5.7 \pm 3.5\end{array}$ & NR & $\begin{array}{l}\text { G1:424.9 } \pm 96.9 \\
G 2: 420.4 \pm 90.7\end{array}$ \\
\hline Manenti et al. (2014) & 10 & $6 / 4$ & $67.1 \pm 7.2$ & $8.1 \pm 3.5$ & $133.3 \pm 5.7$ & $749.2 \pm 445.5$ \\
\hline Schabrun et al. (2016) & 16 & $\begin{array}{l}\text { G1:8/0 } \\
\text { G2:2/6 }\end{array}$ & $\begin{array}{l}\mathrm{G} 1: 72 \pm 4.9 \\
\mathrm{G} 2: 63 \pm 11.0\end{array}$ & $\begin{array}{l}\text { G1:6.9 } \pm 4.4 \\
G 2: 4.6 \pm 3.9\end{array}$ & $\begin{array}{l}\mathrm{G} 1: 47.7 \pm 7.5 \\
\mathrm{G} 2: 37.7 \pm 9.8\end{array}$ & $\begin{array}{l}\mathrm{G} 1: 730 \pm 341 \\
\mathrm{G} 2: 523 \pm 398\end{array}$ \\
\hline $\begin{array}{l}\text { Fernandez-Lago et al. } \\
(2017)\end{array}$ & 18 & $11 / 7$ & $56.67 \pm 11.63$ & $6.17 \pm 3.65$ & NR & $733.2 \pm 496.2$ \\
\hline Lattari et al. (2017) & 17 & $13 / 4$ & $69.18 \pm 9.8$ & $7.06 \pm 2.70$ & $18.0 \pm 8.96$ & $748.29 \pm 343.80$ \\
\hline Yotnuengnit et al. (2018) & 53 & $\begin{array}{l}\text { G1:11/6 } \\
\text { G2:12/6 } \\
\text { G3:10/8 }\end{array}$ & $\begin{array}{l}\text { G1:68.2 } \pm 9.8 \\
\text { G2:62.7 } \pm 8.8 \\
\text { G3:64.4 } \pm 7.8\end{array}$ & $\begin{array}{l}\text { G1:9.4 } \pm 5.3 \\
\text { G2:6.6 } \\
\text { G3:7.9 } \\
\text { G } 3.9\end{array}$ & $\begin{array}{l}\text { G1: } 11.94 \pm 4.68 \\
G 2: 11.17 \pm 3.97 \\
G 3: 10.89 \pm 4.75\end{array}$ & $\begin{array}{l}\text { G1:829.0 } \pm 360.6 \\
G 2: 912.0 \pm 472.9 \\
G 3: 849.1 \pm 397.1\end{array}$ \\
\hline Costa-Ribeiro et al. (2017) & 22 & $\begin{array}{l}\text { G1:8/3 } \\
\text { G2:7/4 }\end{array}$ & $\begin{array}{l}\text { G1:61.1 } \pm 9.1 \\
G 2: 62.0 \pm 16.7\end{array}$ & $\begin{array}{l}\text { G1:6.1 } \pm 3.8 \\
G 2: 6.3 \pm 3.7\end{array}$ & $\begin{array}{l}\mathrm{G} 1: 19.0 \pm 4.9 \\
\mathrm{G} 2: 17.6 \pm 5.1\end{array}$ & $\begin{array}{l}\text { G1:740.9 } \pm 924.3 \\
G 2: 890.9 \pm 836.0\end{array}$ \\
\hline Swank et al. (2016) & 10 & $8 / 2$ & $68.7 \pm 10.2$ & $7.9 \pm 7.1$ & NR & NR \\
\hline Kaski et al. (2014b) & 16 & NR & NR & NR & NR & NR \\
\hline Lawrence et al. (2018) & 28 & $\begin{array}{l}\text { G1:2/5 } \\
\text { G2:4/3 } \\
\text { G3:3/4 } \\
\text { G4:2/5 }\end{array}$ & $\begin{array}{c}\text { G1:63.57 } \pm 15.68 \\
\text { G2:68.14 } \pm 8.69 \\
\text { G3:72.29 } \pm 6.21 \\
\text { G4:72 } \pm 6.45\end{array}$ & $\begin{array}{l}\text { G2:6.79 } \pm 4.6 \\
\text { G2:5.29 } \pm 4.23 \\
\text { G3:5.36 } \pm 4.14 \\
\text { G4:5.50 } \pm 5.66\end{array}$ & NR & $\begin{array}{c}\text { G1:350.71 } \pm 322.37 \\
\text { G2:295 } \pm 313.40 \\
\text { G3:292.88 } \pm 274.51 \\
\text { G4:573.29 } \pm 586.25\end{array}$ \\
\hline Benninger et al. (2010) & 15 & $\begin{array}{l}\text { G1:9/4 } \\
\text { G2:7/5 }\end{array}$ & $\begin{array}{c}G 1: 53.56 \pm 11.5 \\
G 2: 55.1 \pm 8.7\end{array}$ & $\begin{array}{c}G 1: 10.6 \pm 7.1 \\
G 2: 9.1 \pm 3.3\end{array}$ & NR & NR \\
\hline Bueno et al. (2019) & 20 & $8 / 12$ & $64.45 \pm 8.98$ & $7.80 \pm 5.32$ & $22.35 \pm 6.77$ & NR \\
\hline Manenti et al. (2018) & 22 & $\begin{array}{l}\text { G1:5/6 } \\
\text { G2:7/4 }\end{array}$ & $\begin{array}{l}\text { G1:65.5 } \pm 6.4 \\
\text { G2:63.8 } \pm 7.1\end{array}$ & $\begin{array}{l}\text { G1:6.2 } \pm 3.9 \\
G 2: 7.6 \pm 3.4\end{array}$ & $\begin{array}{l}\text { G1: } 26 \pm 10.3 \\
\text { G2: } 22.7 \pm 7.8\end{array}$ & $\begin{array}{l}\text { G1:618.6 } \pm 304.4 \\
G 2: 559.8 \pm 306.5\end{array}$ \\
\hline
\end{tabular}

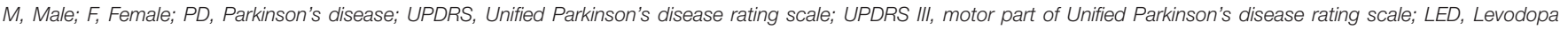
equivalent dose; G, group; G1, Experimental group 1; G2, Control group 1, G3, Control group2, G4, Experimental group 2, NR, Not Reported. 
TABLE 2 | tDCS protocols of the included studies.

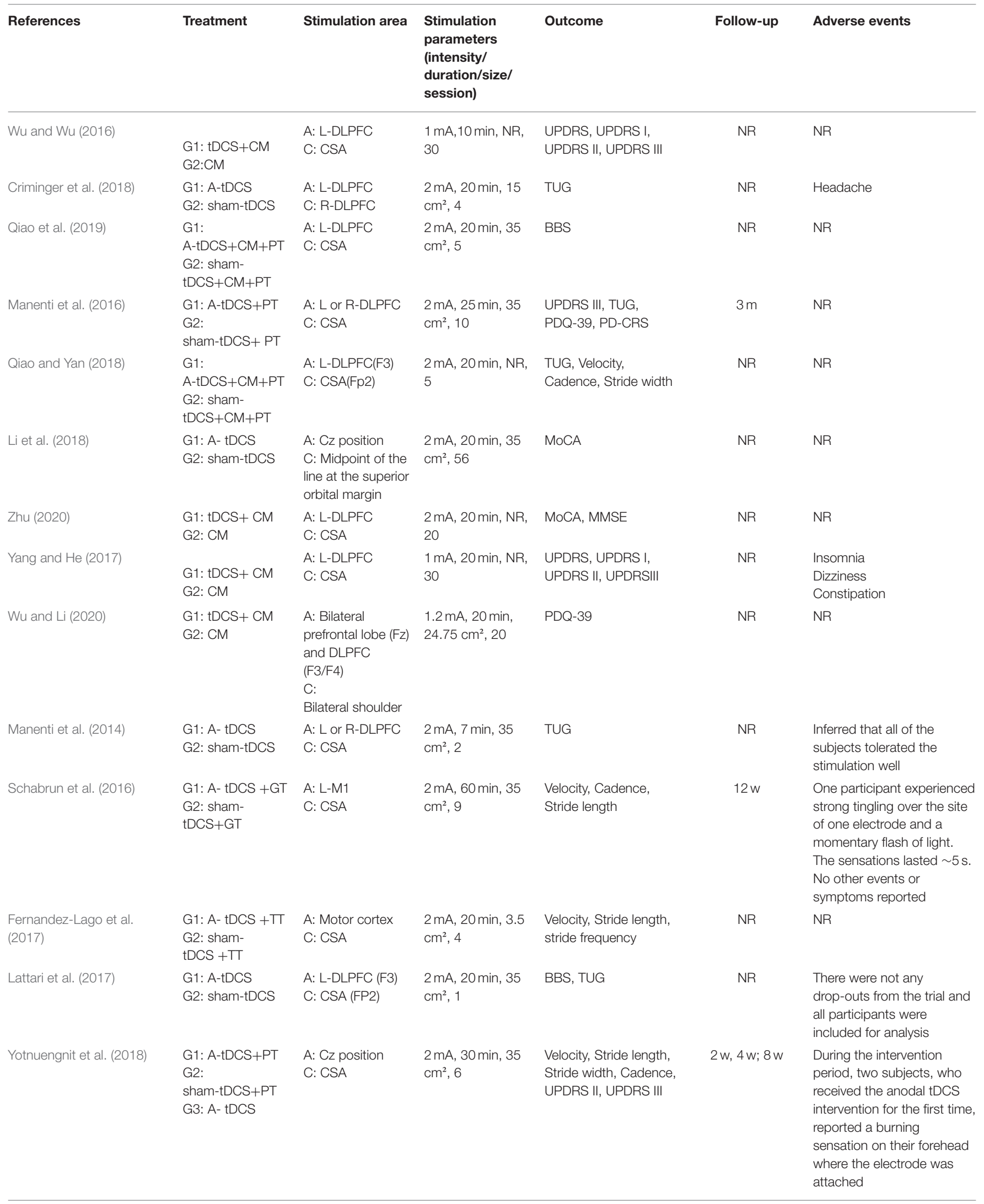


TABLE 2 | Continued

\begin{tabular}{|c|c|c|c|c|c|c|}
\hline References & Treatment & Stimulation area & $\begin{array}{l}\text { Stimulation } \\
\text { parameters } \\
\text { (intensity/ } \\
\text { duration/size/ } \\
\text { session) }\end{array}$ & Outcome & Follow-up & Adverse events \\
\hline Costa-Ribeiro et al. (2017) & $\begin{array}{l}\text { G1: A- tDCS+GT } \\
\text { G2: sham- } \\
\text { tDCS+GT }\end{array}$ & $\begin{array}{l}\text { A: placed } 2 \mathrm{~cm} \\
\text { anterior to the } \\
\text { vertex (Cz } \\
\text { position, EEG } \\
\text { 10/20 system) } \\
\text { C: AHAS }\end{array}$ & $\begin{array}{l}2 \mathrm{~mA}, 13 \mathrm{~min}, \mathrm{NR}, \\
10\end{array}$ & $\begin{array}{l}\text { TUG, Velocity, Cadence } \\
\text { Stride-length, UPDRS } \\
\text { III, BBS, PDQ-39 }\end{array}$ & $1 \mathrm{~m}$ & $\begin{array}{l}\text { No adverse events were } \\
\text { reported by any of the } \\
\text { participants }\end{array}$ \\
\hline Swank et al. (2016) & $\begin{array}{l}\text { G1: A- tDCS } \\
\text { G2: sham-tDCS }\end{array}$ & $\begin{array}{l}\text { A: L-DLPFC } \\
\text { C: R-DLPFC }\end{array}$ & $\begin{array}{l}2 \mathrm{~mA}, 20 \mathrm{~min}, \mathrm{NR}, \\
1\end{array}$ & TUG & NR & $\begin{array}{l}\text { All participants completed } \\
\text { the study. }\end{array}$ \\
\hline Kaski et al. (2014b) & $\begin{array}{l}\text { G1: A- } \\
\text { tDCS+GBT } \\
\text { G2: sham- } \\
\text { tDCS+GBT }\end{array}$ & $\begin{array}{l}\text { A: M1 } \\
\text { C: Inion }\end{array}$ & $\begin{array}{l}2 \mathrm{~mA}, 15 \mathrm{~min}, 40 \\
\mathrm{~cm}^{2}(\mathrm{~A}) \\
16 \mathrm{~cm}^{2}(\mathrm{C}) \\
\mathrm{NR}\end{array}$ & $\begin{array}{l}\text { Velocity, Stride length, } \\
\text { TUG }\end{array}$ & NR & NR \\
\hline Lawrence et al. (2018) & $\begin{array}{l}\text { G1: tDCS+CT } \\
\text { G2: CT } \\
\text { G3: Nothing } \\
\text { G4: tDCS }\end{array}$ & $\begin{array}{l}\text { A: L-DLPFC } \\
\text { C: Over the left eye }\end{array}$ & $\begin{array}{l}1.5 \mathrm{~mA}, 20 \mathrm{~min}, 35 \\
\mathrm{~cm}^{2}, 12\end{array}$ & $\begin{array}{l}\text { PDQ-39, PD-CRS, } \\
\text { MMSE }\end{array}$ & $12 w$ & $N R$ \\
\hline Benninger et al. (2010) & $\begin{array}{l}\text { G1: A- tDCS } \\
\text { G2: sham-tDCS }\end{array}$ & $\begin{array}{l}\text { A: premotor and } \\
\text { motor or PFC } \\
\text { C: PFC or } \\
\text { premotor } \\
\text { and motor }\end{array}$ & $\begin{array}{l}2 \mathrm{~mA}, 20 \mathrm{~min}, 24.5 \\
\mathrm{~cm}^{2}(\mathrm{~A}) \\
25 \mathrm{~cm}^{2}(\mathrm{C}) \\
8\end{array}$ & UPDRS, UPDRS III & $1 \mathrm{~m} ; 3 \mathrm{~m}$ & $\begin{array}{l}\text { Small first degree burns } \\
\text { over the mastoids partially } \\
\text { covering the earlobes with } \\
\text { reduced contact surface } \\
\text { resulting in an increased } \\
\text { current density which healed } \\
\text { completely within } 3 \text { days }\end{array}$ \\
\hline Bueno et al. (2019) & $\begin{array}{l}\text { G1: A- tDCS } \\
\text { G2: sham-tDCS }\end{array}$ & $\begin{array}{l}\text { A: L-DLPFC (F3) } \\
\text { C: right orbital } \\
\text { frontal cortex (Fp2) }\end{array}$ & $\begin{array}{l}2 \mathrm{~mA}, 20 \mathrm{~min}, 35 \\
\mathrm{~cm}^{2}, 1\end{array}$ & TUG, Velocity, Cadence & NR & $\begin{array}{l}\text { All subjects demonstrated } \\
\text { good tolerability toward the } \\
\text { application of the stimulation } \\
\text { without exhibiting any } \\
\text { adverse effects }\end{array}$ \\
\hline Manenti et al. (2018) & $\begin{array}{l}\text { G1: A- tDCS } \\
\text { +CCT } \\
\text { G2: sham- } \\
\text { tDCS +CCT }\end{array}$ & $\begin{array}{l}\text { A: L-DLPFC } \\
\text { (F3) } \\
\text { C: over the right } \\
\text { Supraorbital area }\end{array}$ & $\begin{array}{l}2 \mathrm{~mA}, 25 \mathrm{~min}, 35 \\
\mathrm{~cm}^{2}, 10\end{array}$ & $\begin{array}{l}\text { UPDRS III, PDQ-39, } \\
\text { PD-CRS }\end{array}$ & $3 m$ & Not mentioned in the article \\
\hline
\end{tabular}

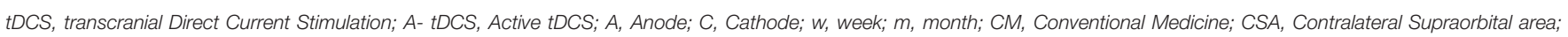

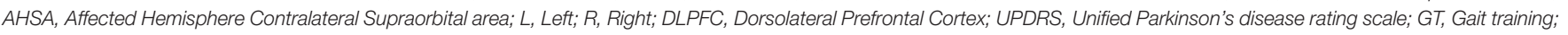

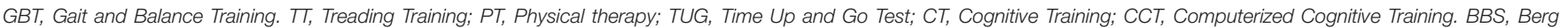

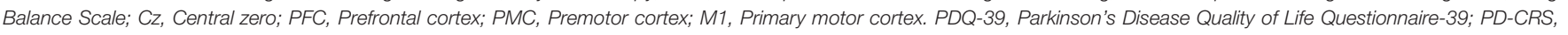
Parkinson Disease-Cognitive Rating Scale; MoCA, Montreal Cognitive Assessment; MMSE, Mini-mental State Examination; NR, Not Reported.

The heterogeneity between each group was tested using the $I^{2}$ test and Cochran's $Q$ statistic (Zintzaras and Ioannidis, 2005). Less than $25 \%$ of the $I^{2}$ values indicate low heterogeneity, $25-50 \%$ indicate moderate heterogeneity, and $>50 \%$ indicate high heterogeneity. A random-effects model was applied if high heterogeneity was observed ( $p<0.05$ or $I^{2}>50 \%$ ); otherwise, a fixed-effects model was applied ( $p>0.05$ or $\left.I^{2}<50 \%\right)$. When significant heterogeneity was present, subgroup analysis and sensitivity analysis were performed on the data, and if the source of heterogeneity could not be determined, descriptive analysis was performed.

\section{RESULTS}

\section{Study Classification}

Figure 1 shows the flow diagram for the selection of the included studies.
We searched out a total of 357 records from the relevant databases. First, 217 duplicated records were excluded, and 140 remained. Then, we read the articles carefully. In addition, 119 articles were excluded for the following reasons: review or metaanalysis $(n=20)$, not related to tDCS $(n=15)$, related to other disease $(n=26)$, not RCTs $(n=16)$, not a full-text article $(n=5)$, animal experiment $(n=9)$, and no original data $(n=28)$. Finally, 21 studies were eventually included in this review.

\section{Characteristics of the Included Studies}

The participants and the methodological characteristics of the included studies are shown in Tables 1, 2. A total of 21 articles (all in all, 736 patients with PD) were included in this systematic review, of which $66.7 \%$ were by foreign authors and the remaining $33.3 \%$ were reported in a Chinese database. Twelve out of the 21 studies reported the drug status of participants, while the remaining nine did not mention the medication status. 


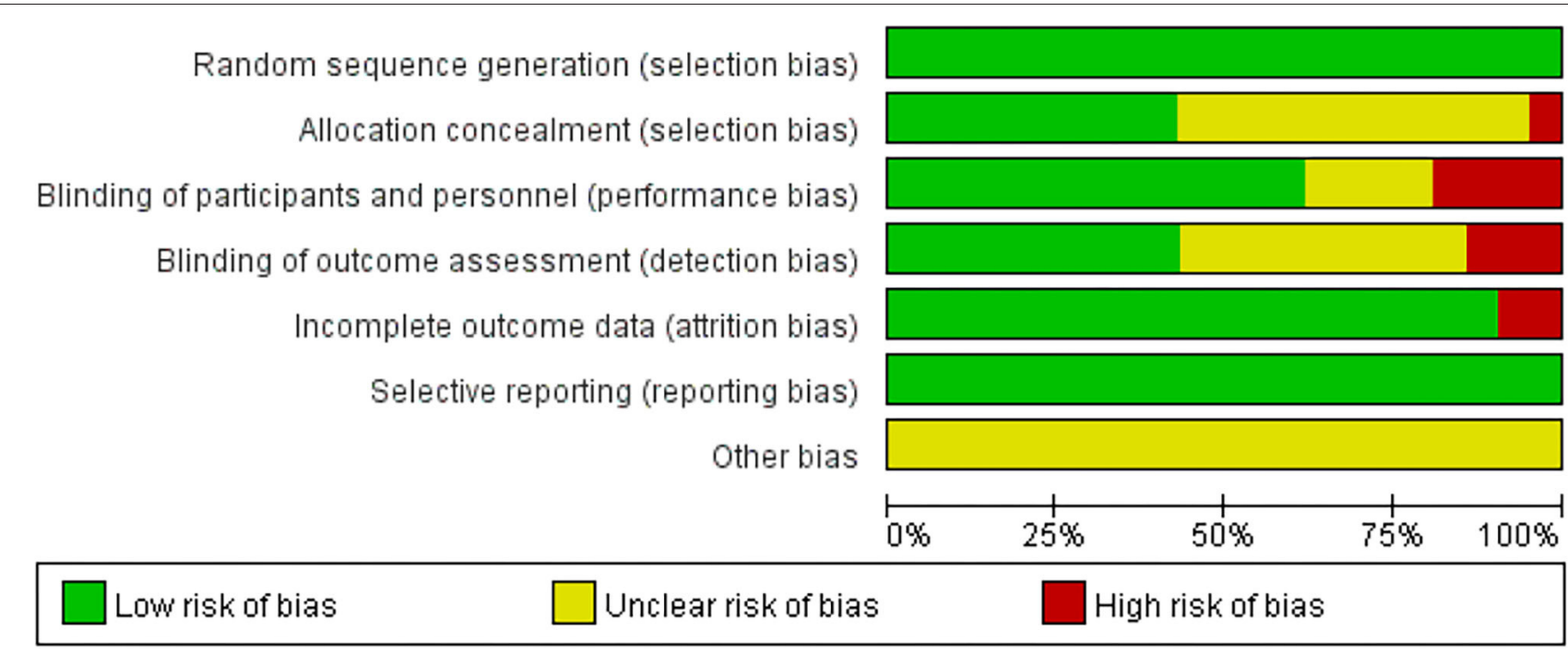

FIGURE 2 | Risk of bias of the included studies.

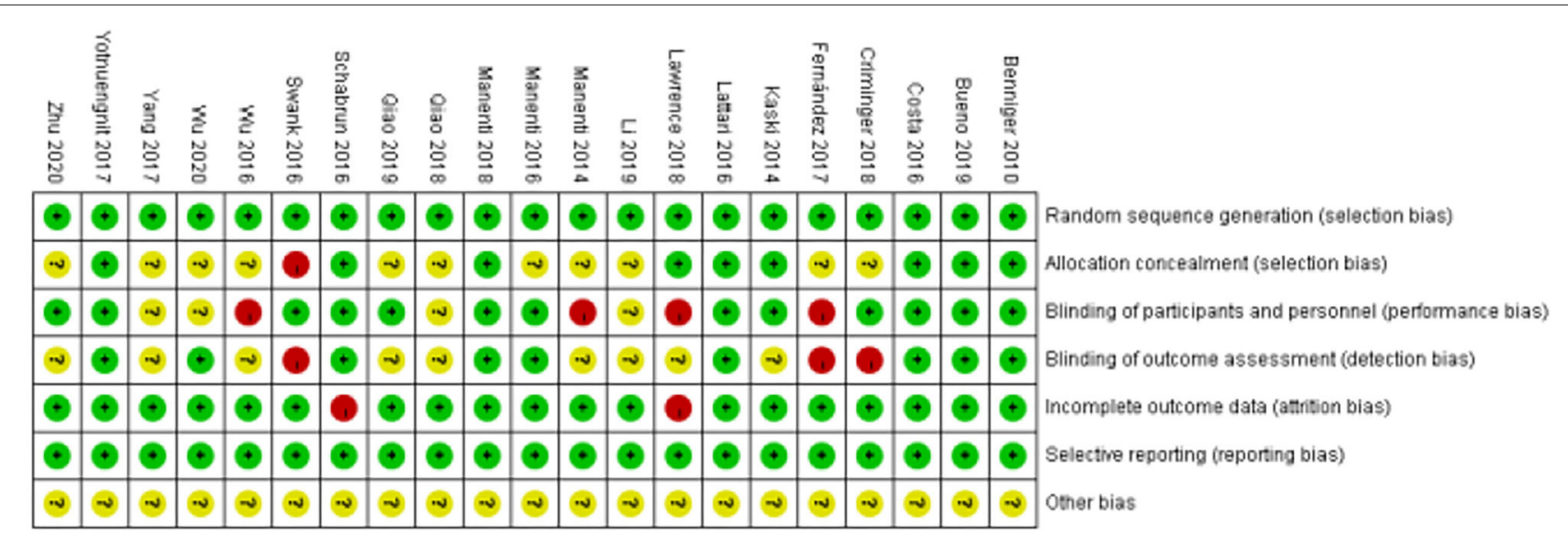

FIGURE 3 | Risk of bias summary of the included studies.

Among the 21 included studies, all received active tDCS or sham tDCS alone, or in combination with other treatments. The stimulation area of the brain includes the dorsolateral prefrontal cortex (DLPFC), the primary motor cortex (M1), prefrontal cortex (PFC), premotor cortex (PMC), and central zero $(\mathrm{Cz})$ position. Among these areas, the DLPFC was the most frequently stimulated site, with 13 studies out of 21, followed by M1 (four studies), PFC, PMC, and $\mathrm{Cz}$ position. Finally, 17 studies applied repeated sessions of tDCS protocols, three studies used a single session of $\mathrm{tDCS}$, and one study did not report.

\section{Methodological Quality}

The details of the risk of bias of all the included studies are shown in Figures 2, 3. All the articles used the random method to generate sequences. In the allocation concealment, only one study was high risk and nine studies were low risk. For the blinding of the outcome assessment, three retrieved studies were high risk and nine were unclear. During the evaluation process, we found that two articles mentioned patients who dropped out but were not included in the analysis, which may increase the risk of bias. In addition, all the studies clearly described selective reporting.

\section{Unified Parkinson's Disease Rating Scale III (UPDRS III)}

The UPDRS III was used as an outcome measure in seven of the 21 studies. The UPDRS III scores of the seven studies showed a non-significant effect size $(-0.13 ; 95 \% \mathrm{CI}=-0.64,0.38 ; p=0.61$; $\left.I^{2}=77 \%\right)$ (Figure 4$)$. Due to the high heterogeneity $\left(I^{2}=77 \%\right)$, we performed a subgroup analysis of the stimulus parameters. For the duration of the stimulus, there were five articles $\geq 20 \mathrm{~min}$ $(\mathrm{SMD}=-0.09 ; 95 \% \mathrm{CI}=-0.69,0.52 ; p=0.78)$ and two articles $<20 \min (\mathrm{SMD}=-0.17 ; 95 \% \mathrm{CI}=-1.63,1.30 ; p=0.83)$, all of which did not show a significant pooled effect size (Figure 4). 


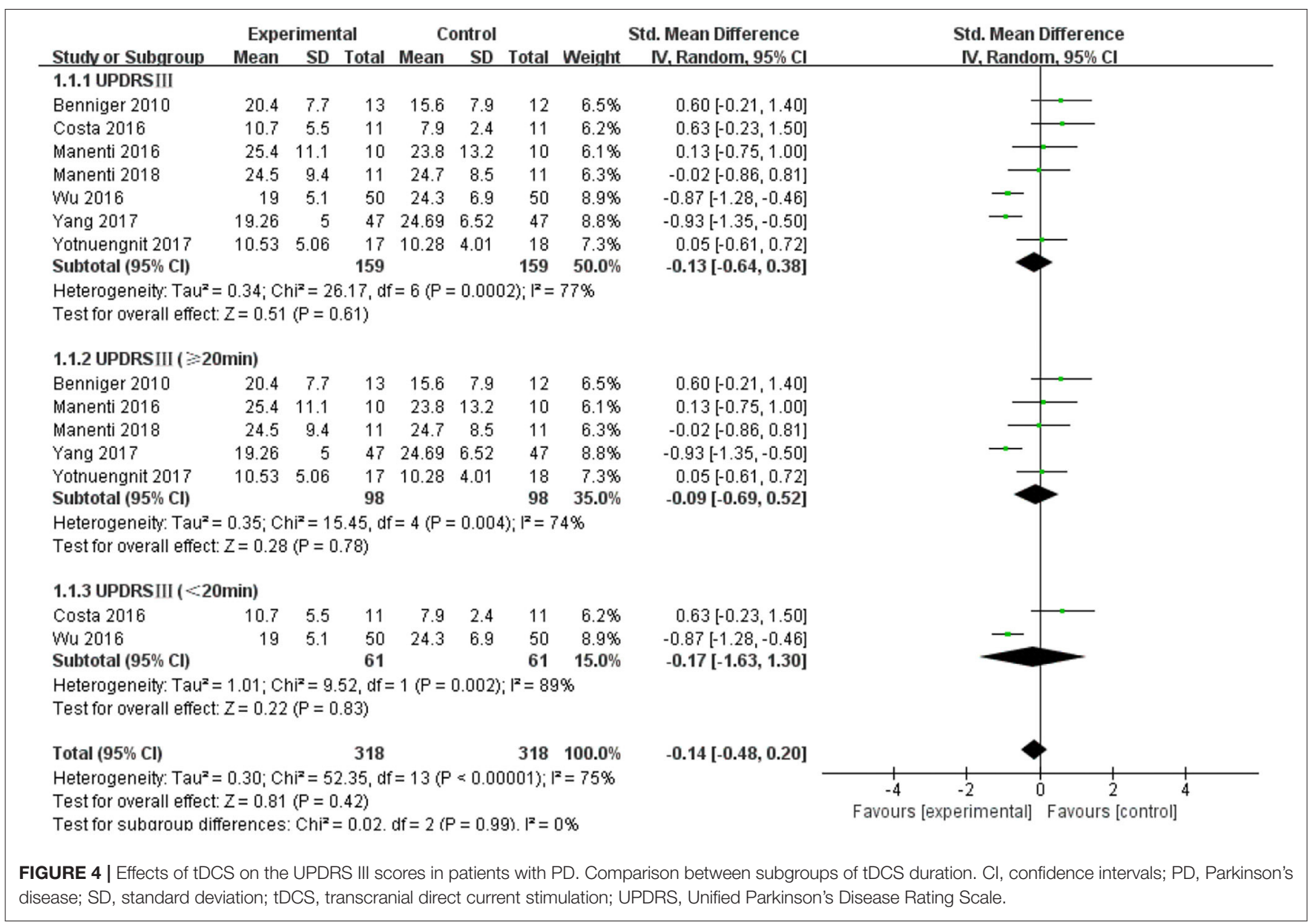

For stimulus intensity, there were five articles at $2 \mathrm{~mA}$ and there was a non-significant pooled effect size $(\mathrm{SMD}=0.26 ; 95 \% \mathrm{CI}=$ $\left.-0.10,-0.61 ; p=0.16 ; I^{2}=0 \%\right)$. Two articles measuring $<2 \mathrm{~mA}$ showed a significant pooled effect size $(\mathrm{SMD}=-0.90 ; 95 \% \mathrm{CI}=$ $-1.19,-0.60 ; p<0.00001 ; I^{2}=0 \%$ ) (Figure 5). The two studies were identical in terms of the stimulus location (left DLPFC and contralateral supraorbital area) and result evaluation (UPDRS), with different intensities. Wu and Wu (2016) used $1 \mathrm{~mA}$ current for $10 \mathrm{~min}$, while Yang and $\mathrm{He}$ (2017) used $1 \mathrm{~mA}$ for $20 \mathrm{~min}$. For the stimulation session, there were two articles with fewer than 10 sessions $\left(\mathrm{SMD}=0.27 ; 95 \% \mathrm{CI}=-0.25,0.80 ; p=0.30 ; I^{2}=4 \%\right)$ and five articles with 10 or more sessions (SMD $=-0.31 ; 95 \%$ $\mathrm{CI}=-0.88,0.25 ; p=0.28)$, none of which showed effectiveness (Figure 6).

\section{Time Up and go Test (TUG) and Berg Balance Scale (BBS)}

The TUG test was used as an evaluation standard. Nine studies employed the TUG test. The meta-analysis showed an insignificant pooled effect size $(-0.12 ; 95 \% \mathrm{CI}=-0.43,0.19 ; p=$ $0.46 ; I^{2}=0 \%$ ) (Figure 7). Three studies used the BBS. The result was non-significant as that of the TUG, and the pooled effect size was $\mathrm{SMD}=-0.03 ; 95 \% \mathrm{CI}=-0.45$ to $0.39 ; p=0.88)($ Figure 7$)$.

\section{Velocity, Cadence, Stride Length, and Stride Width}

Gait parameters, including velocity, cadence, stride length, and stride width, were measured as the outcomes of tDCS in patients with PD. Seven studies used velocity, and a non-significant effect was shown (Figure 8A) $(\mathrm{SMD}=-0.04 ; 95 \% \mathrm{CI}=-0.35,0.27$; $\left.p=0.80 ; I^{2}=0 \%\right)$. Five studies used cadence, and this metaanalysis showed a non-significant pooled effect size $(-0.15 ; 95 \%$ $\mathrm{CI}=-0.55,0.25 ; p=0.46 ; I^{2}=18 \%$ ) (Figure 8B). Five studies reported stride length, and the results showed that tDCS was not effective in improving the step length of patients with PD. The effect size of SMD $=0.24,95 \%$ CI was -0.14 to $0.62, p=0.21, I^{2}$ $=0 \%$ (Figure $8 \mathrm{C}$ ). Two studies used stride width as the outcome measure, and the meta-analysis of these data also showed no significant effect $(\mathrm{SMD}=0.50,95 \% \mathrm{CI}=-0.86$ to $1.87 ; p=0.47$; $\left.I^{2}=86 \%\right)$ (Figure 8D).

\section{MMSE, MoCA, PD-CRS, and UPDRS I}

The non-motor symptoms of PD mainly include cognitive dysfunction and emotional disorders, and they seriously affect the quality of the daily lives of patients with PD. In this meta-analysis, MoCA, MMSE, PD-CRS, and UPDRS I were used. The MoCA scale showed a significant effect on improving cognitive functions in the included articles, and the effect size was SMD $=0.87,95 \%$ 


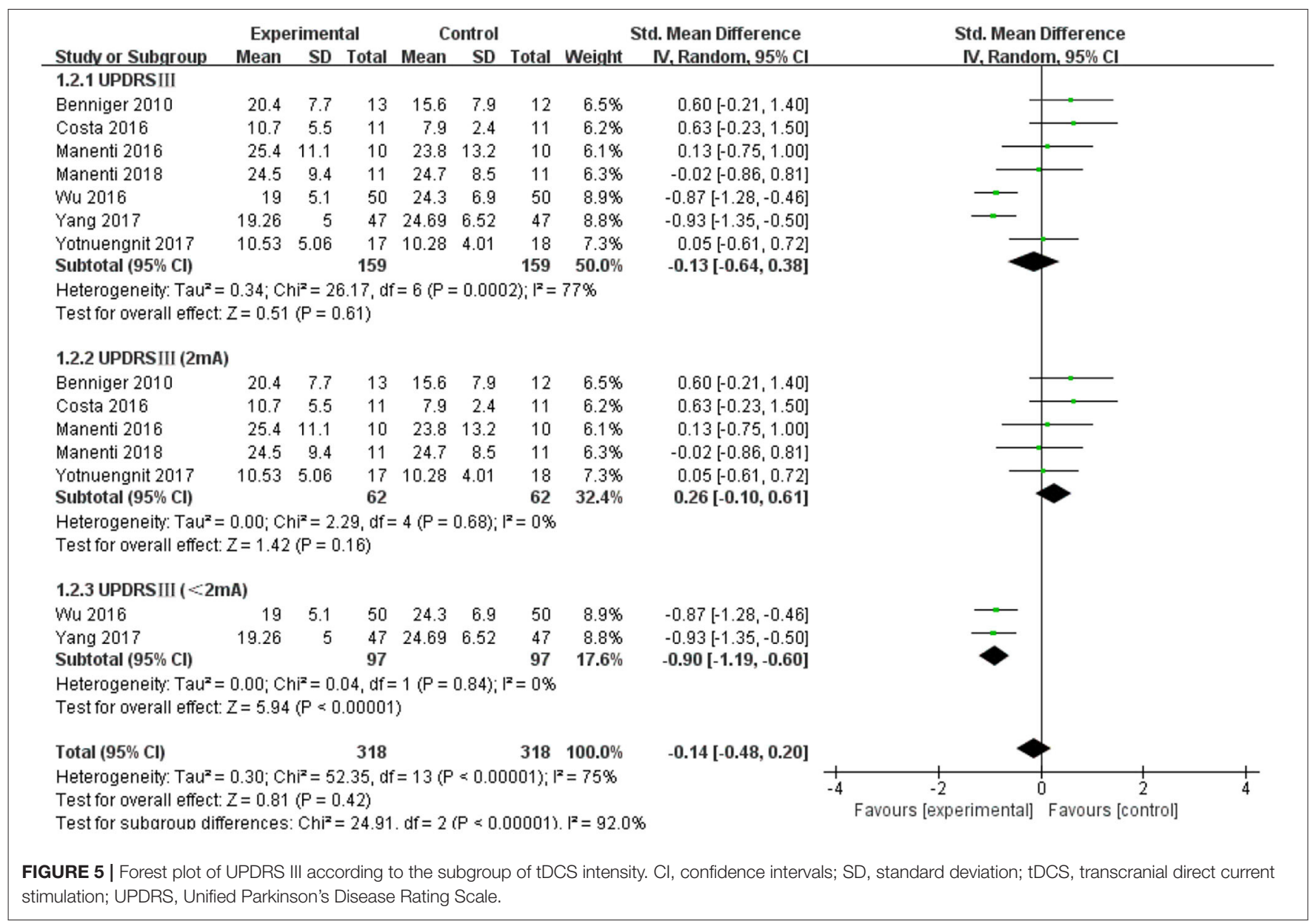

$\mathrm{CI}=0.50$ to $1.24 ; p<0.00001 ; I^{2}=0 \%$ (Figure 9B). For UPDRS I, two studies showed a significant pooled effect size $(-1.29 ; 95 \%$ $\mathrm{CI}=-1.60,-0.98 ; p<0.00001 ; I^{2}=0 \%$ ) (Figure 9D). However, the MMSE and PD-CRS showed a non-significant pooled effect size. The MMSE was SMD $=0.55,95 \% \mathrm{CI}=-0.04$ to $1.14 ; p$ $=-0.07 ; I^{2}=26 \%$ (Figure 9A), and the PD-CRS was SMD = $0.37 ; 95 \% \mathrm{CI}=-0.16$ to $0.90 ; p=0.17 ; I^{2}=0 \%$ (Figure 9C). These results may be due to the tDCS parameters and severity of the disease. Lawrence et al. (2018) used a $1.5 \mathrm{~mA}$ current for $20 \mathrm{~min}$ in 12 sessions; Zhu (2020) used $2 \mathrm{~mA}$ for $20 \mathrm{~min}$ in 20 sessions, while Manenti et al. $(2016,2018)$ used $2 \mathrm{~mA}$ for $25 \mathrm{~min}$, for a total of 10 sessions. The duration of PD included in their studies varied greatly. The average duration was $3.785 \pm 2.16$ in Zhu's study (2020), $7.45 \pm 3.9$ in Manenti et al. (2016), 6.9 \pm 3.65 in Manenti et al. (2018), and $5.81 \pm 4.32$ in Lawrence et al. (2018). Due to these differences, the effects of tDCS on these factors were inconsistent.

\section{PDQ-39 and UPDRS II}

In this systematic review, four studies were included to analyze whether tDCS can improve the self-care ability of patients with $\mathrm{PD}$ in daily life, and the results were non-effective (SMD $=-0.35$, $95 \% \mathrm{CI}=-1.24$ to $0.54 ; p=0.44 ; I^{2}=79 \%$ ) (Figure 10A). Three studies selected UPDRS II as an outcome measure, and this metaanalysis found a non-significant pooled effect size $(-0.64 ; 95 \% \mathrm{CI}$ $=-1.46,0.19 ; p=0.13 ; I^{2}=88 \%$ ) (Figure 10B).

\section{Adverse Events}

Adverse events were reported in five studies. Yang and $\mathrm{He}$ (2017) reported that both the experimental group and the control group experienced adverse events, including insomnia, dizziness, postural hypotension, and constipation, with an incidence rate of $20.21 \%$. In Criminger et al. (2018), one patient developed a headache. In Schabrun et al. (2016), one participant experienced a strong tingling and a momentary flash of light over the area of one electrode, and the sensations lasted for about $5 \mathrm{~s}$. Yotnuengnit et al. (2018) mentioned that during the intervention period, two participants experienced a burning sensation on their forehead skin. In Benninger et al. (2010), one subject had a small number of first-degree burns. However, none of these adverse events resulted in serious consequences in any of the included studies.

\section{DISCUSSION}

The present systematic review of clinical studies of tDCS in PD aimed to evaluate the efficacy of tDCS as a clinical therapy 


\begin{tabular}{|c|c|c|c|c|c|c|c|c|c|c|c|}
\hline \multirow[b]{2}{*}{ Studv or Subgroup } & \multicolumn{3}{|c|}{ Experimental } & \multicolumn{2}{|c|}{ Control } & \multirow{2}{*}{\multicolumn{2}{|c|}{ Total Weight }} & \multirow{2}{*}{$\begin{array}{l}\text { Std. Mean Difference } \\
\quad \text { N. Random, } 95 \% \mathrm{Cl}\end{array}$} & \multirow{2}{*}{\multicolumn{3}{|c|}{$\begin{array}{l}\text { Std. Mean Difference } \\
\text { IV, Random, } 95 \% \mathrm{Cl}\end{array}$}} \\
\hline & Mean & SD & Total & Mean & SD & & & & & & \\
\hline \multicolumn{12}{|l|}{ 1.3.1 UPDRS III } \\
\hline Benniger 2010 & 20.4 & 7.7 & 13 & 15.6 & 7.9 & 12 & $6.5 \%$ & $0.60[-0.21,1.40]$ & & & \\
\hline Costa 2016 & 10.7 & 5.5 & 11 & 7.9 & 2.4 & 11 & $6.2 \%$ & $0.63[-0.23,1.50]$ & & & \\
\hline Manenti 2016 & 25.4 & 11.1 & 10 & 23.8 & 13.2 & 10 & $6.1 \%$ & $0.13[-0.75,1.00]$ & & & \\
\hline Manenti 2018 & 24.5 & 9.4 & 11 & 24.7 & 8.5 & 11 & $6.3 \%$ & $-0.02[-0.86,0.81]$ & & & \\
\hline Wu 2016 & 19 & 5.1 & 50 & 24.3 & 6.9 & 50 & $8.9 \%$ & $-0.87[-1.28,-0.46]$ & $=$ & & \\
\hline Yang 2017 & 19.26 & 5 & 47 & 24.69 & 6.52 & 47 & $8.8 \%$ & $-0.93[-1.35,-0.50]$ & $\longrightarrow$ & & \\
\hline Yotnuengnit 2017 & 10.53 & 5.06 & 17 & 10.28 & 4.01 & 18 & $7.3 \%$ & $0.05[-0.61,0.72]$ & & & \\
\hline Subtotal $(95 \% \mathrm{Cl})$ & & & 159 & & & 159 & $50.0 \%$ & $-0.13[-0.64,0.38]$ & & & \\
\hline \multicolumn{12}{|c|}{$\begin{array}{l}\text { Heterogeneity: } \text { Tau }^{2}=0.34 ; \mathrm{Chi}^{2}=26.17, \mathrm{df}=6(\mathrm{P}=0.0002) ; \mathrm{I}^{2}=77 \% \\
\text { Test for overall effect: } Z=0.51(P=0.61)\end{array}$} \\
\hline \multicolumn{12}{|c|}{ 1.3.2 UPDRSIII ( $\geqslant 10$ sessions) } \\
\hline Costa 2016 & 10.7 & 5.5 & 11 & 7.9 & 2.4 & 11 & $6.2 \%$ & $0.63[-0.23,1.50]$ & & & \\
\hline Manenti 2016 & 25.4 & 11.1 & 10 & 23.8 & 13.2 & 10 & $6.1 \%$ & $0.13[-0.75,1.00]$ & & & \\
\hline Manenti 2018 & 24.5 & 9.4 & 11 & 24.7 & 8.5 & 11 & $6.3 \%$ & $-0.02[-0.86,0.81]$ & & & \\
\hline Wu 2016 & 19 & 5.1 & 50 & 24.3 & 6.9 & 50 & $8.9 \%$ & $-0.87[-1.28,-0.46]$ & - & & \\
\hline Yang 2017 & 19.26 & 5 & 47 & 24.69 & 6.52 & 47 & $8.8 \%$ & $-0.93[-1.35,-0.50]$ & & & \\
\hline Subtotal $(95 \% \mathrm{Cl})$ & & & 129 & & & 129 & $36.2 \%$ & $-0.31[-0.88,0.25]$ & & & \\
\hline \multicolumn{12}{|c|}{$\begin{array}{l}\text { Heterogeneity: } \operatorname{Tau}^{2}=0.29 ; \mathrm{Chi}^{2}=16.25, \mathrm{df}=4(\mathrm{P}=0.003) ; \mathrm{I}^{2}=75 \% \\
\text { Test for overall effect: } Z=1.09(\mathrm{P}=0.28)\end{array}$} \\
\hline \multicolumn{12}{|c|}{ 1.3.3 UPDRSIII (<10sessions) } \\
\hline Benniger 2010 & 20.4 & 7.7 & 13 & 15.6 & 7.9 & 12 & $6.5 \%$ & $0.60[-0.21,1.40]$ & & & \\
\hline Yotnuengnit 2017 & 10.53 & 5.06 & 17 & 10.28 & 4.01 & 18 & $7.3 \%$ & $0.05[-0.61,0.72]$ & & & \\
\hline Subtotal $(95 \% \mathrm{Cl})$ & & & 30 & & & 30 & $13.8 \%$ & $0.27[-0.25,0.80]$ & & & \\
\hline \multicolumn{12}{|c|}{$\begin{array}{l}\text { Heterogeneity: } \operatorname{Tau}^{2}=0.01 ; \mathrm{Chi}^{2}=1.04, \mathrm{df}=1(\mathrm{P}=0.31) ; \mathrm{I}^{2}=4 \% \\
\text { Test for overall effect: } Z=1.03(\mathrm{P}=0.30)\end{array}$} \\
\hline Total $(95 \% \mathrm{Cl})$ & & & 318 & & & 318 & $100.0 \%$ & $-0.14[-0.48,0.20]$ & & & \\
\hline \multicolumn{9}{|c|}{$\begin{array}{l}\text { Heterogeneity: } \operatorname{Tau}^{2}=0.30 ; \mathrm{Chi}^{2}=52.35, \mathrm{df}=13(\mathrm{P}=0.00001) ; \mathrm{I}^{2}=75 \% \\
\text { Test for overall effect: } Z=0.81(\mathrm{P}=0.42) \\
\text { Test for subaroun differences: } \mathrm{Ch}^{2}=2.42 . \mathrm{df}=2(\mathrm{P}=0.30) . \mathrm{I}^{2}=17.4 \%\end{array}$} & $-4 \quad-2$ & 0 Favours [control] & 4 \\
\hline
\end{tabular}

for PD based on the existing evidence. In this review, the high heterogeneity of stimulation parameters does not allow us to firmly conclude that tDCS improves cognitive performance. In addition, it is uncertain whether tDCS can improve motor function in patients with PD. Further studies with larger sample sizes are needed to explore this possibility more thoroughly. Below, we discuss the effect of tDCS on motor and nonmotor functions.

The 21 studies included were consistent in terms of the tDCS areas. In all studies, electrodes were placed to target the brain regions associated with motor or cognitive function. The studies aimed at improving cognition in the DLPFC or PFC, and the studies aimed to improve motor function in patients with PD employed electrodes at the M1 or premotor cortex. Fourteen studies used the DLPFC as the stimulation area. The DLPFC is considered to be the central region of executive functions in humans, and patients with damage to this region may show cognitive difficulties in organizing behavioral responses, extracting memory, and generating motor programs. The metaanalysis showed that tDCS could have a significant therapeutic effect on cognitive performance. Although the sample size was relatively small, the results of this meta-analysis extend the previous findings that the tDCS protocol may improve cognitive function in PD (Doruk et al., 2014; Biundo et al., 2015). This may be related to the cortical excitability enhanced by anode tDCS (Broeder et al., 2015). Transcranial direct current stimulation, as a non-invasive method of brain stimulation, can promote cerebral cortical blood flow (Cosmo et al., 2015). Polardependent shifts are capable of generating resting membrane potentials at the neuronal level (Broeder et al., 2015). In relation to this, the stimulation of the cortex by tDCS may promote the neural connectivity between the cortical and subcortical network, and improve neuroplasticity in patients with PD (Bindman et al., 1964; Nitsche and Paulus, 2000). Can anode tDCS improve motor function in PD? The results of our meta-analysis showed that tDCS did not significantly improve UPDRS III, TUG, gait, or balance. We attempted to determine the reason for this from the tDCS parameters. For the effect of tDCS on the UPDRS III of PD, we performed a subgroup analysis of the stimulation duration, intensity, and session, and the same results were observed. We also compared the stimulation area of tDCS, the number of subjects included, the severity of the disease, and the status of drug treatment between the studies, and found large differences. Bueno et al. (2019) showed that a single DLPFC 


\begin{tabular}{|c|c|c|c|c|c|c|c|c|c|c|c|}
\hline \multirow[b]{2}{*}{ Studv or Subgroup } & \multicolumn{3}{|c|}{ Experimental } & \multicolumn{2}{|c|}{ Control } & & & Std. Mean Difference & \multirow{2}{*}{\multicolumn{3}{|c|}{$\begin{array}{l}\text { Std. Mean Difference } \\
\text { IV. Random, } 95 \% \mathrm{Cl}\end{array}$}} \\
\hline & Mean & SD & Total & Mean & SD & Total & Weight & IV. Random, $95 \% \mathrm{Cl}$ & & & \\
\hline \multicolumn{12}{|c|}{ 2.1.1 Effect of tDCS on TUG } \\
\hline Bueno 2019 & 8.03 & 2.55 & 10 & 8.06 & 2.24 & 10 & $8.2 \%$ & $-0.01[-0.89,0.86]$ & & & \\
\hline Costa 2016 & 10.2 & 5.4 & 11 & 9 & 2.2 & 11 & $8.9 \%$ & $0.28[-0.56,1.12]$ & & & \\
\hline Criminger 2018 & 9.49 & 2.42 & 8 & 9.44 & 3.3 & 8 & $6.5 \%$ & $0.02[-0.96,1.00]$ & & & \\
\hline Kaski 2014 & 9.5 & 3.1 & 8 & 9.37 & 1.5 & 8 & $6.5 \%$ & $0.05[-0.93,1.03]$ & & & \\
\hline Lattari 2016 & 24.35 & 18.97 & 9 & 29.18 & 2.17 & 8 & $6.8 \%$ & $-0.33[-1.29,0.63]$ & & & \\
\hline Manenti 2014 & 10.28 & 3.08 & 5 & 11.19 & 3.17 & 5 & $4.0 \%$ & $-0.26[-1.51,0.99]$ & & & \\
\hline Manenti 2016 & 9.14 & 1.4 & 10 & 10.8 & 1.9 & 10 & $7.2 \%$ & $-0.95[-1.89,-0.02]$ & & & \\
\hline Qiao 2018 & 9.67 & 2.27 & 15 & 9.57 & 2.6 & 15 & $12.2 \%$ & $0.04[-0.68,0.76]$ & & & \\
\hline Swank 2016 & 9.62 & 2.62 & 5 & 10.24 & 3.26 & 5 & $4.1 \%$ & $-0.19[-1.43,1.05]$ & & & \\
\hline Subtotal $(95 \% \mathrm{Cl})$ & & & 81 & & & 80 & $64.4 \%$ & $-0.12[-0.43,0.19]$ & & & \\
\hline \multicolumn{12}{|c|}{$\begin{array}{l}\text { Heterogeneity: } \text { Tau }^{2}=0.00 ; \mathrm{Chi}^{2}=4.59, \mathrm{df}=8(\mathrm{P}=0.80) ; \mathrm{I}^{2}=0 \% \\
\text { Test for overall effect: } Z=0.74(\mathrm{P}=0.46)\end{array}$} \\
\hline \multicolumn{12}{|c|}{ 2.1.2 Effect of tDCS on BBS } \\
\hline Costa 2016 & 54.1 & 2.8 & 11 & 55 & 1.4 & 11 & $8.8 \%$ & $-0.39[-1.24,0.45]$ & & & \\
\hline Lattari 2016 & 42.82 & 12.17 & 9 & 41.06 & 12.28 & 8 & $6.9 \%$ & $0.14[-0.82,1.09]$ & & & \\
\hline Qiao 2019 & 52.24 & 4.04 & 25 & 51.96 & 4.11 & 24 & $20.0 \%$ & $0.07[-0.49,0.63]$ & & & \\
\hline Subtotal $(95 \% \mathrm{Cl})$ & & & 45 & & & 43 & $35.6 \%$ & $-0.03[-0.45,0.39]$ & & & \\
\hline \multicolumn{12}{|c|}{$\begin{array}{l}\text { Heterogeneity: } \text { Tau }^{2}=0.00 ; \mathrm{Chi}^{2}=0.93, \mathrm{df}=2(\mathrm{P}=0.63) ; \mathrm{I}^{2}=0 \% \\
\text { Test for overall effect: } Z=0.15(\mathrm{P}=0.88)\end{array}$} \\
\hline Total $(95 \% \mathrm{Cl})$ & & & 126 & & & 123 & $100.0 \%$ & $-0.09[-0.34,0.16]$ & & & \\
\hline \multicolumn{9}{|c|}{$\begin{array}{l}\text { Heterogeneity: } \mathrm{Tau}^{2}=0.00 ; \mathrm{Chi}^{2}=5.63, \mathrm{df}=11(\mathrm{P}=0.90) ; \mathrm{I}^{2}=0 \% \\
\text { Test for overall effect: } Z=0.68(\mathrm{P}=0.50) \\
\text { Test for subaroun differences: } \mathrm{Ch}^{2}=0.10 . \mathrm{df}=1(\mathrm{P}=0.75) . \mathrm{I}^{2}=0 \%\end{array}$} & $\begin{array}{ccc}-2 & -1 & 1 \\
\text { Favours [experimental] } & F\end{array}$ & $\begin{array}{c}1 \\
\text { Favours [control] }\end{array}$ & 2 \\
\hline
\end{tabular}

stimulation was insufficient to promote gait changes in PD patients, and they argued that the assessment tools used in the study do not represent the gold standard and may not be sensitive enough to detect changes. Therefore, we believe that many factors contribute to the tDCS induced improvement of motor functions in patients with PD. However, some studies have demonstrated the effectiveness of tDCS in improving the motor function of patients with PD. In Qiao and Yan (2018), the anode stimulation of the left DLPFC in terms of the step width resulted in a significant difference between tDCS and sham intervention, suggesting that $\mathrm{tDCS}$ intervention can improve bradykinesia in patients with early PD to a certain extent. In previous studies (Schabrun et al., 2016), the anode stimulation of tDCS was found to improve the cadence of PD. Wu and Wu (2016) and Yang and $\mathrm{He}$ (2017) also showed that the stimulation of the left DLPFC with anode tDCS can improve the scores of the UPDRS III in PD. In one case (Kaski et al., 2014a) report of a patient with moderate $\mathrm{PD}$, while dancing the tango, the peak velocity of the trunk was significantly greater than the sham stimulation upon stimulating anode tDCS the primary and premotor cortex. This may be because tDCS intervention triggers the motor and prefrontal cortex regions, which may lead to the release of dopamine in patients with $\mathrm{PD}$ and promote the improvement of motor functions (Voon et al., 2009; Manenti et al., 2016; Lee et al., 2019). Another possible mechanism is that cerebellar tDCS improves sensorimotor functions through either cerebellobrain inhibition or dentate disinhibition (Ferrucci et al., 2016; Kimpel et al., 2020). Hence, there was insufficient evidence to demonstrate the effectiveness of tDCS in improving the motor functions of patients with PD. More sensitive tests, such as a three-dimensional gait analysis system or electromyography, are needed to assess motor functions in the future. This is consistent with the conclusions drawn from a review by Nardone et al. (2020). Future research should identify the optimal stimulation targets for motor function in patients with PD.

In this review, 17 studies used $2 \mathrm{~mA}$ stimulus intensity, and none compared the effects of different tDCS intensities on PD. Why choose $2 \mathrm{~mA}$ stimulation intensity? Possibly because some studies have shown that $2 \mathrm{~mA}$ stimulation increases cortical excitability more than $1 \mathrm{~mA}$ stimulation (Shekhawat et al., 2013; Murray et al., 2015). In Beretta et al. (2020b), the anode tDCS stimulation of M1 improved the ability of patients with PD to respond to external interference, and $2 \mathrm{~mA}$ showed more improvement than $1 \mathrm{~mA}$. However, other studies have found that, for anode tDCS, regardless of the current intensity of 1 or $2 \mathrm{~mA}$, the amplitudes of the motor-evoked potentials did not change significantly (Tremblay et al., 2016; Jamil et al., 2017). In addition, in our meta-analysis, the results suggested that the intensity of stimulation does not affect UPDRS III; nevertheless, high heterogeneity was noted. We conducted a subgroup analysis, which showed that a current stimulation of $<2 \mathrm{~mA}$ had a more positive effect than the stimulation of $2 \mathrm{~mA}$ on the UPDRS III, which is inconsistent with the clinical observations. This may be due to the small sample size and the higher risk of bias in the included articles. Therefore, further research is needed to understand whether the intensity of tDCS is an important 


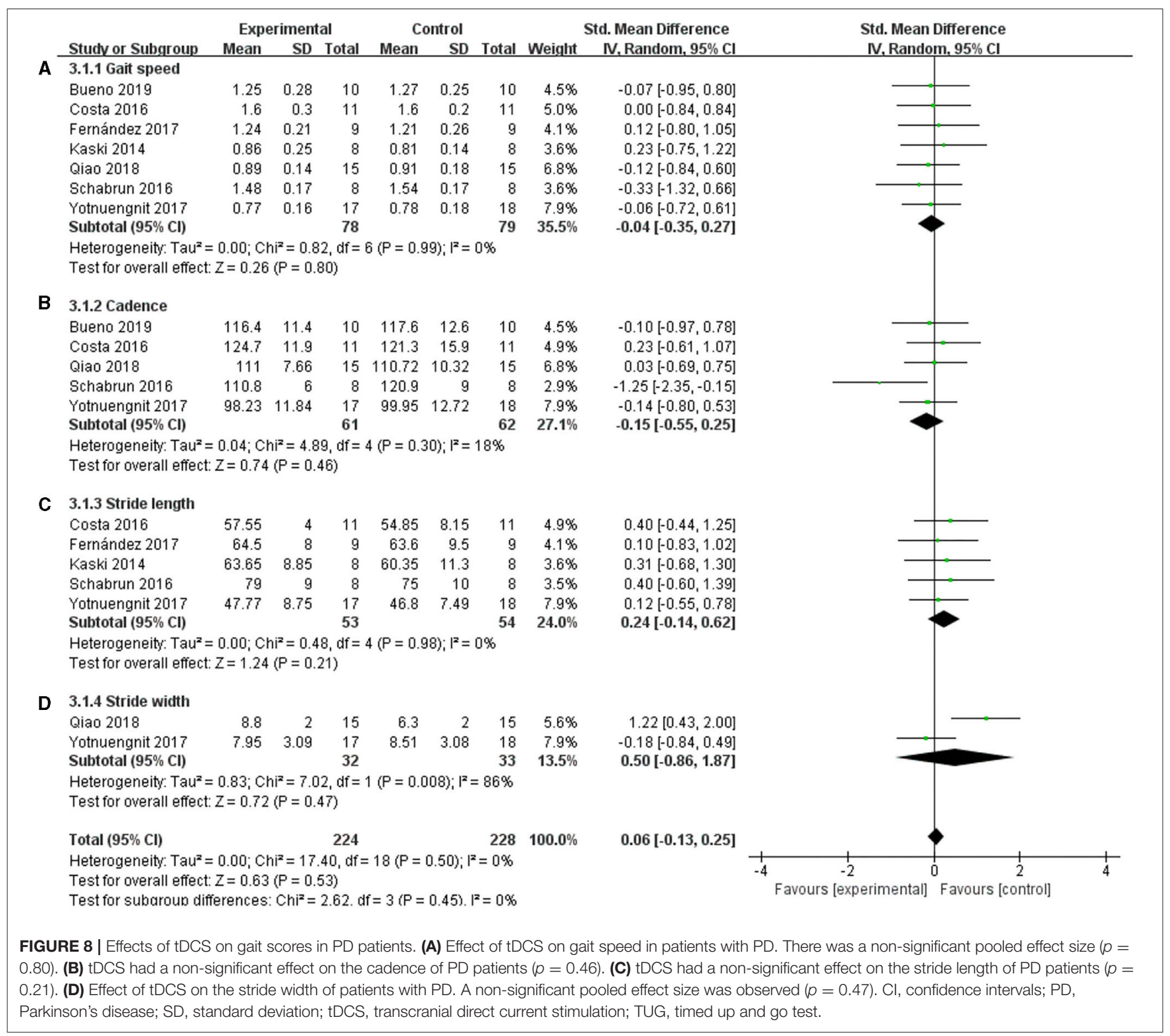

factor affecting the results. None of the included studies used stimulation of more than $2 \mathrm{~mA}$. However, in Agboada et al. (2019), an increase in excitability was observed from the lower to higher current intensities ( 1 vs. $3 \mathrm{~mA}$ ). Therefore, further studies on the tolerance and efficacy of this method should be conducted in the future.

The stimulation duration of the tDCS protocol differed among the included studies from 7 to $30 \mathrm{~min}$. This large difference may explain the obvious differences in effects. Regarding the stimulation duration, although most studies used tDCS for $20 \mathrm{~min}$, positive results for shorter stimulation durations have also been reported. Kaski et al. (2014b) found that placing the anode $\mathrm{tDCS}$ over the primary motor cortex for $15 \mathrm{~min}$ combined with physical activity had significant benefits for gait speed and balance. Nitsche and Paulus (2001) reported that 5-13 min of anode tDCS on the motor cortex leads to increased motorevoked potentials. Another study reported that increasing the tDCS duration would be necessary to increase the magnitude or duration of plasticity (Tremblay et al., 2016). Agboada et al. (2019) reported that there was no significant correlation between therapeutic effect and stimulation durations. In this review, the association between stimulation duration and efficacy in patients with PD was not determined; therefore, it is necessary to conduct a more comprehensive evaluation of the effect of the duration of tDCS on PD treatment.

In most studies in this review, repeated sessions were conducted, but some studies have shown that a single tDCS on the left DLPFC in patients with PD can improve balance 


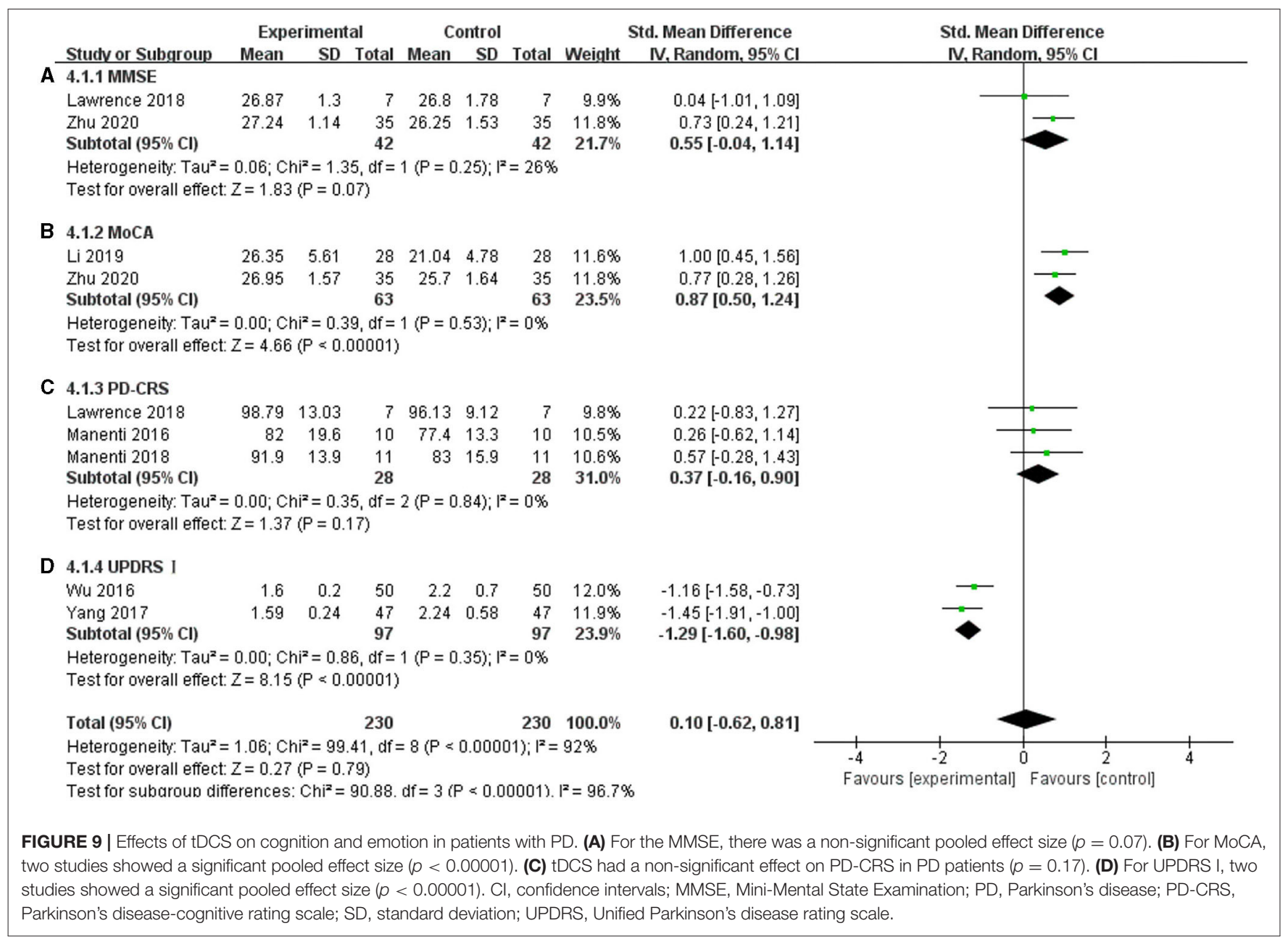

and functional activity (Lattari et al., 2017). A meta-analysis showed that compared with mono-target stimulations, multitarget stimulation showed significant improvements in mobility, balance, gait velocity, and fall reduction (Orrù et al., 2019). Whether single or repetitive stimulation is more effective is still uncertain, and the effect of tDCS sessions on the treatment of PD needs to be further evaluated. Compared with the therapeutic effects of tDCS on single stimulation, multiple stimulations in PD functional rehabilitation will likely become a hot research topic in the future. The PDQ-39 and UPDRS II were used to assess the quality of life of the subjects. In Manenti et al. (2018), no significant difference in the PDQ-39 scores was observed between the experimental and control groups. This may be because daily activities are complex motor manifestations that require a combination of motor and cognitive abilities, as well as other functional capabilities.

In the analysis of the included studies, several limitations affect the results. First, the quality of the studies was relatively moderate. Second, the sample size was small, making it difficult to generalize the results. Third, there was high heterogeneity in the research design of the included articles and tDCS protocol, which makes it difficult to determine the most suitable protocol for improving the clinical symptoms of PD. Finally, only Chinese and English literature were included, and the risk of article selection may affect the comprehensiveness of the results.

Therefore, in the future, more multi-level and multi-center authoritative controlled studies with large samples are needed. The determination and unification of the tDCS treatment parameters, the establishment of the sham stimulation group, and determination of the curative effect and treatment mechanism, all need to be explored in more detail, and treatment standards and norms should be issued to guide clinical practice.

\section{CONCLUSION}

The results showed that tDCS appears to improve cognitive performance, but there is insufficient evidence to demonstrate that tDCS is effective in the treatment of the motor function of patients with PD. Further multicenter research with larger sample sizes is needed. Future research should focus on determining the tDCS parameters that are most beneficial to the functional recovery of patients with $\mathrm{PD}$. 


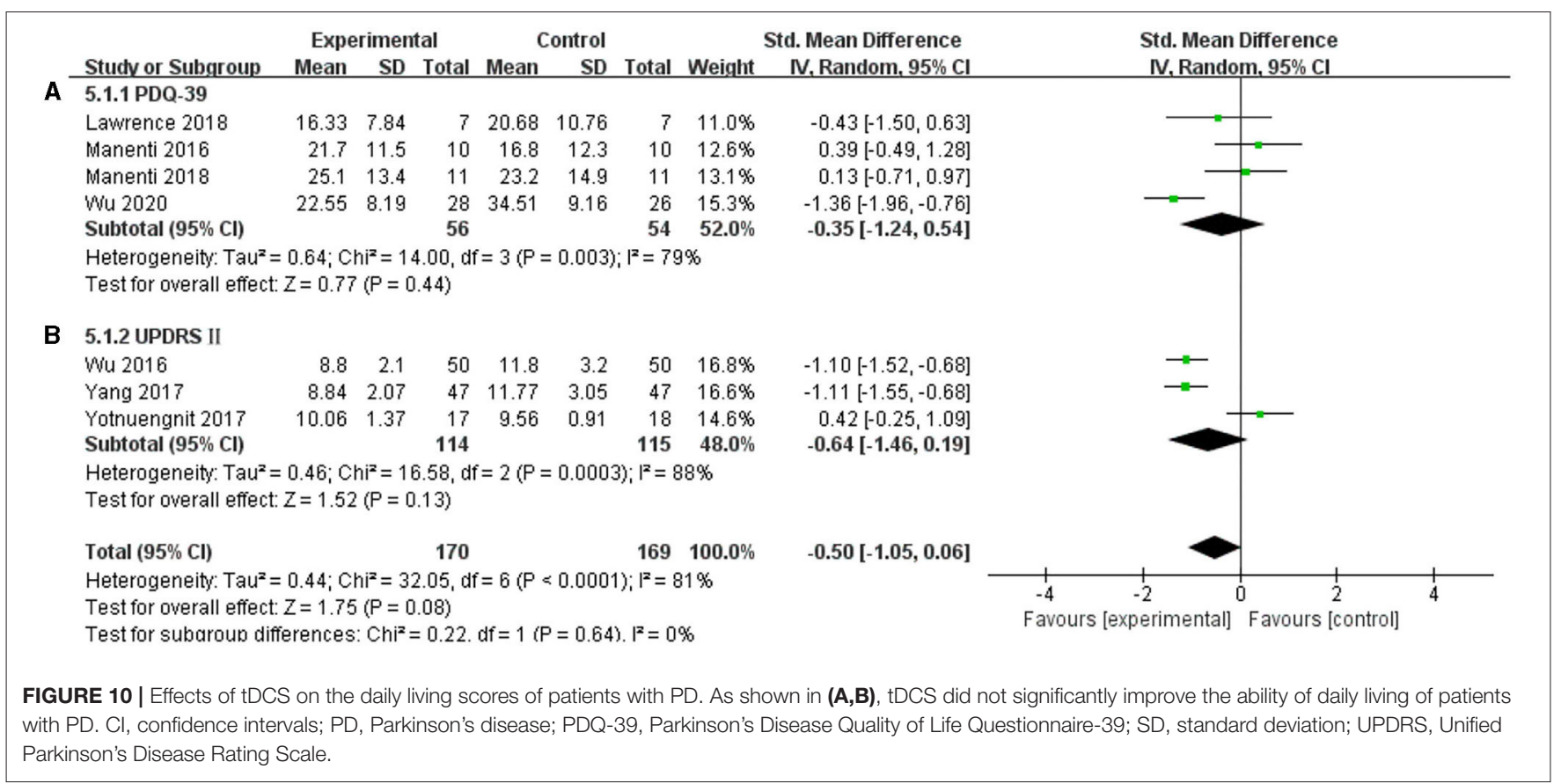

\section{DATA AVAILABILITY STATEMENT}

The original contributions presented in the study are included in the article/supplementary material, further inquiries can be directed to the corresponding author/s.

\section{AUTHOR CONTRIBUTIONS}

PW, XG, and YW: conceptualization and writingreview and editing. XL, HL, ZL, JR, JW, PW, XG, and YW: data curation. XL, HL, ZL, JR, JW, PW, and YW: formal analysis, methodology, and writing-original

\section{REFERENCES}

Agboada, D., Mosayebi Samani, M., Jamil, A., Kuo, M. F., and Nitsche, M. A. (2019). Expanding the parameter space of anodal transcranial direct current stimulation of the primary motor cortex. Sci. Rep. 9:18185. doi: 10.1038/s41598-019-54621-0

Benninger, D. H., Lomarev, M., Lopez, G., Wassermann, E. M., Li, X., Considine, E., et al. (2010). Transcranial direct current stimulation for the treatment of Parkinson's disease. J. Neurol. Neurosurg. Psychiatr. 81, 1105-1111. doi: 10.1136/jnnp.2009.202556

Beretta, V. S., Conceicao, N. R., Nobrega-Sousa, P., Orcioli-Silva, D., Dantas, L., Gobbi, L. T. B., et al. (2020a). Transcranial direct current stimulation combined with physical or cognitive training in people with Parkinson's disease: a systematic review. J. Neuroeng. Rehabil. 17:74. doi: 10.1186/s12984-020-00701-6

Beretta, V. S., Vitorio, R., Nobrega-Sousa, P., Conceicao, N. R., Orcioli-Silva, D., Pereira, M. P., et al. (2020b). Effect of different intensities of transcranial direct current stimulation on postural response to external perturbation in patients with Parkinson's disease. Neurorehabil. Neural Repair 34, 1009-1019. doi: $10.1177 / 1545968320962513$ draft. PW and XG: investigation. HL, PW, and XG: project administration. XL, HL, ZL, and JR: software. All authors contributed to the article and approved the submitted version.

\section{ACKNOWLEDGMENTS}

The authors thank the Yuebei People's Hospital, 7th Affiliated Hospital, Sun Yat-sen University, and School of Rehabilitation Medicine, Gannan Medical University for assisting with the systematic review.

Berg, D., Postuma, R. B., Bloem, B., Chan, P., Dubois, B., Gasser, T., et al. (2014). Time to redefine PD? Introductory statement of the MDS Task Force on the definition of Parkinson's disease. Mov. Disord. 29, 454-462. doi: $10.1002 / \mathrm{mds} .25844$

Beudel, M., and Brown, P. (2016). Adaptive deep brain stimulation in Parkinson's disease. Parkinsonism Relat. Disord. 22(Suppl.1), S123-S126. doi: 10.1016/j.parkreldis.2015.09.028

Bindman, L. J., Lippold, O. C., and Redfearn, J. W. (1964). The action of brief polarizing currents on the cerebral cortex of the rat (1) during current flow and (2) in the production of long-lasting after-effects. J. Physiol. 172, 369-382. doi: 10.1113/jphysiol.1964.sp007425

Biundo, R., Weis, L., Fiorenzato, E., Gentile, G., Giglio, M., Schifano, R., et al. (2015). Double-blind randomized trial of tDCS vs. sham in Parkinson patients with mild cognitive impairment receiving cognitive training. Brain Stimul. 8, 1223-1225. doi: 10.1016/j.brs.2015.0 7.043

Boggio, P. S., Ferrucci, R., Rigonatti, S. P., Covre, P., Nitsche, M., PascualLeone, A., et al. (2006). Effects of transcranial direct current stimulation on working memory in patients with Parkinson's disease. J. Neurol. Sci. 249, 31-38. doi: 10.1016/j.jns.2006.05.062 
Broeder, S., Nackaerts, E., Heremans, E., Vervoort, G., Meesen, R., Verheyden, G., et al. (2015). Transcranial direct current stimulation in Parkinson's disease: neurophysiological mechanisms and behavioral effects. Neurosci. Biobehav. Rev. 57, 105-117. doi: 10.1016/j.neubiorev.2015.08.010

Bueno, M. E. B., Do Nascimento Neto, L. I., Terra, M. B., Barboza, N. M., Okano, A. H., and Smaili, S. M. (2019). Effectiveness of acute transcranial direct current stimulation on non-motor and motor symptoms in Parkinson's disease. Neurosci. Lett. 696, 46-51. doi: 10.1016/j.neulet.2018.12.017

Cosmo, C., Ferreira, C., Miranda, J. G., Do Rosário, R. S., Baptista, A. F., and Montoya, P. (2015). Spreading effect of tDCS in individuals with attentiondeficit/hyperactivity disorder as shown by functional cortical networks: a randomized, double-blind, sham-controlled trial. Front. Psychiatr. 6:111. doi: 10.3389/fpsyt.2015.00111

Costa-Ribeiro, A., Maux, A., Bosford, T., Aoki, Y., Castro, R., Baltar, A., et al. (2017). Transcranial direct current stimulation associated with gait training in Parkinson's disease: a pilot randomized clinical trial. Dev. Neurorehabil. 20, 121-128. doi: 10.3109/17518423.2015.1131755

Criminger, C., Swank, C., Almutairi, S., and Mehta, J. (2018). Transcranial direct current stimulation plus concurrent activity may influence task prioritization during walking in people with Parkinson's disease - initial findings. J. Parkinsonism Restless Legs Syndrome 8, 25-32. doi: 10.2147/JPRLS.S161740

Dorsey, E. R., Elbaz, A., Nichols, E., Abd-Allah, F., Abdelalim, A., Adsuar, J. C., et al. (2018). Global, regional, and national burden of Parkinson's disease, 1990-2016: a systematic analysis for the Global Burden of Disease Study 2016. Lancet Neurol. 17, 939-953. doi: 10.1016/S1474-4422(18)30295-3

Doruk, D., Gray, Z., Bravo, G. L., Pascual-Leone, A., and Fregni, F. (2014). Effects of tDCS on executive function in Parkinson's disease. Neurosci. Lett. 582, 27-31. doi: 10.1016/j.neulet.2014.08.043

Fernandez-Lago, H., Bello, O., Mora-Cerda, F., Montero-Camara, J., and Fernandez-Del-Olmo, M. A. (2017). Treadmill walking combined with anodal transcranial direct current stimulation in Parkinson's disease: a pilot study of kinematic and neurophysiological effects. Am. J. Phys. Med. Rehabil. 96, 801-808. doi: 10.1097/PHM.0000000000000751

Ferrucci, R., Cortese, F., Bianchi, M., Pittera, D., Turrone, R., Bocci, T., et al. (2016). Cerebellar and motor cortical transcranial stimulation decrease levodopa-induced dyskinesias in Parkinson's disease. Cerebellum 15, 43-47. doi: 10.1007/s12311-015-0737-x

Goodwill, A. M., Lum, J. a. G., Hendy, A. M., Muthalib, M., Johnson, L., AlbeinUrios, N., et al. (2017). Using non-invasive transcranial stimulation to improve motor and cognitive function in Parkinson's disease: a systematic review and meta-analysis. Sci. Rep. 7:14840. doi: 10.1038/s41598-017-13260-z

Gray, S. L., Anderson, M. L., Dublin, S., Hanlon, J. T., Hubbard, R., Walker, R., et al. (2015). Cumulative use of strong anticholinergics and incident dementia: a prospective cohort study. J. Am. Med. Assoc. Intern. Med. 175, 401-407. doi: 10.1001/jamainternmed.2014.7663

Guidetti, M., Marceglia, S., Loh, A., Harmsen, I. E., Meoni, S., Foffani, G., et al. (2021). Clinical perspectives of adaptive deep brain stimulation. Brain Stimul. 14, 1238-1247. doi: 10.1016/j.brs.2021.07.063

Higgins, J. P., Altman, D. G., Gotzsche, P. C., Juni, P., Moher, D., Oxman, A. D., et al. (2011). The Cochrane Collaboration's tool for assessing risk of bias in randomised trials. BMJ 343:d5928. doi: 10.1136/bmj.d5928

Jamil, A., Batsikadze, G., Kuo, H. I., Labruna, L., Hasan, A., Paulus, W., et al. (2017). Systematic evaluation of the impact of stimulation intensity on neuroplastic after-effects induced by transcranial direct current stimulation. J. Physiol. 595, 1273-1288. doi: 10.1113/JP272738

Jankovic, J. (2008). Parkinson's disease: clinical features and diagnosis. J. Neurol. Neurosurg. Psychiatr. 79, 368-376. doi: 10.1136/jnnp.2007.131045

Jankovic, J., and Stacy, M. (2007). Medical management of levodopa-associated motor complications in patients with Parkinson's disease. CNS Drugs 21, 677-692. doi: 10.2165/00023210-200721080-00005

Kaski, D., Allum, J. H., Bronstein, A. M., and Dominguez, R. O. (2014a). Applying anodal tDCS during tango dancing in a patient with Parkinson's disease. Neurosci. Lett. 568, 39-43. doi: 10.1016/j.neulet.2014.03.043

Kaski, D., Dominguez, R. O., Allum, J. H., Islam, A. F., and Bronstein, A. M. (2014b). Combining physical training with transcranial direct current stimulation to improve gait in Parkinson's disease: a pilot randomized controlled study. Clin. Rehabil. 28, 1115-1124. doi: 10.1177/0269215514534277
Kimpel, O., Hulst, T., Batsikadze, G., Ernst, T. M., Nitsche, M. A., Timmann, D., et al. (2020). Long-term effects of cerebellar anodal transcranial direct current stimulation (tDCS) on the acquisition and extinction of conditioned eyeblink responses. Sci. Rep. 10:22434. doi: 10.1038/s41598-020-80023-8

Lattari, E., Costa, S. S., Campos, C., De Oliveira, A. J., Machado, S., and Maranhao Neto, G. A. (2017). Can transcranial direct current stimulation on the dorsolateral prefrontal cortex improves balance and functional mobility in Parkinson's disease? Neurosci. Lett. 636, 165-169. doi: 10.1016/j.neulet.2016.11.019

Lawrence, B. J., Gasson, N., Johnson, A. R., Booth, L., and Loftus, A. M. (2018). Cognitive training and transcranial direct current stimulation for mild cognitive impairment in Parkinson's disease: a randomized controlled trial. Parkinson's Dis. 2018:4318475. doi: 10.1155/2018/4318475

Lee, H. K., Ahn, S. J., Shin, Y. M., Kang, N., and Cauraugh, J. H. (2019). Does transcranial direct current stimulation improve functional locomotion in people with Parkinson's disease? A systematic review and meta-analysis. J. Neuroeng. Rehabil. 16:84. doi: 10.1186/s12984-019-0562-4

Lefaucheur, J. P., Antal, A., Ayache, S. S., Benninger, D. H., Brunelin, J., Cogiamanian, F., et al. (2017). Evidence-based guidelines on the therapeutic use of transcranial direct current stimulation (tDCS). Clin. Neurophysiol. 128, 56-92. doi: 10.1016/j.clinph.2016.10.087

Li, X., and Zhang, J. H. (2018). Effects of transcranial direct current stimulation on cognitive function and auditory event-related potentials in patients with Parkinson's disease. Chin. J. Phys. Med. Rehabil. 40, 198-201. doi: 10.3389/fnhum.2021.653713

Manenti, R., Brambilla, M., Benussi, A., Rosini, S., Cobelli, C., Ferrari, C., et al. (2016). Mild cognitive impairment in Parkinson's disease is improved by transcranial direct current stimulation combined with physical therapy. Mov. Disord. 31, 715-724. doi: $10.1002 / \mathrm{mds} .26561$

Manenti, R., Brambilla, M., Rosini, S., Orizio, I., Ferrari, C., Borroni, B., et al. (2014). Time up and go task performance improves after transcranial direct current stimulation in patient affected by Parkinson's disease. Neurosci. Lett. 580, 74-77. doi: 10.1016/j.neulet.2014.07.052

Manenti, R., Cotelli, M. S., Cobelli, C., Gobbi, E., Brambilla, M., Rusich, D., et al. (2018). Transcranial direct current stimulation combined with cognitive training for the treatment of Parkinson Disease: a randomized, placebocontrolled study. Brain Stimul. 11, 1251-1262. doi: 10.1016/j.brs.2018.07.046

Miniussi, C., Harris, J. A., and Ruzzoli, M. (2013). Modelling non-invasive brain stimulation in cognitive neuroscience. Neurosci. Biobehav. Rev. 37, 1702-1712. doi: 10.1016/j.neubiorev.2013.06.014

Murray, L. M., Edwards, D. J., Ruffini, G., Labar, D., Stampas, A., Pascual-Leone, A., et al. (2015). Intensity dependent effects of transcranial direct current stimulation on corticospinal excitability in chronic spinal cord injury. Arch. Phys. Med. Rehabil. 96, S114-S121. doi: 10.1016/j.apmr.2014.11.004

Nardone, R., Versace, V., Brigo, F., Golaszewski, S., Carnicelli, L., Saltuari, L., et al. (2020). Transcranial magnetic stimulation and gait disturbances in Parkinson's disease: a systematic review. Neurophysiol. Clin. 50, 213-225. doi: 10.1016/j.neucli.2020.05.002

National Collaborating Centre for Chronic, C. (2006). "National Institute for Health and Clinical Excellence: guidance," in Parkinson's Disease: National Clinical Guideline for Diagnosis and Management in Primary and Secondary Care (London: Royal College of Physicians).

Nitsche, M. A., and Paulus, W. (2000). Excitability changes induced in the human motor cortex by weak transcranial direct current stimulation. J. Physiol. 527, 633-639. doi: 10.1111/j.1469-7793.2000.t01-1-0 0633.x

Nitsche, M. A., and Paulus, W. (2001). Sustained excitability elevations induced by transcranial DC motor cortex stimulation in humans. Neurology 57, 1899-1901. doi: 10.1212/WNL.57.10.1899

Nonnekes, J., Arrogi, A., Munneke, M. A., Van Asseldonk, E. H., Oude Nijhuis, L. B., Geurts, A. C., et al. (2014). Subcortical structures in humans can be facilitated by transcranial direct current stimulation. PLoS ONE 9:e107731. doi: 10.1371/journal.pone.0107731

Orrù, G., Baroni, M., Cesari, V., Conversano, C., Hitchcott, P. K., and Gemignani, A. (2019). The effect of single and repeated tDCS sessions on motor symptoms in Parkinson's disease: a systematic review. Arch. Ital. Biol. 157, 89-101. doi: $10.12871 / 00039829201925$ 
Page, M. J., Mckenzie, J. E., Bossuyt, P. M., Boutron, I., Hoffmann, T. C., Mulrow, C. D., et al. (2021). The PRISMA 2020 statement: an updated guideline for reporting systematic reviews. BMJ 372:n71. doi: 10.1136/bmj.n71

Pereira, J. B., Junque, C., Bartres-Faz, D., Marti, M. J., Sala-Llonch, R., Compta, Y., et al. (2013). Modulation of verbal fluency networks by transcranial direct current stimulation (tDCS) in Parkinson's disease. Brain Stimul. 6, 16-24. doi: 10.1016/j.brs.2012.01.006

Qiao, N., Lu, J. J., and Guo, Y. (2019). Effect on balance function in Patients with Parkinson's disease treated by transcranial direct current stimulation. Rehabil. Med. 29, 22-26. doi: 10.3724/SP.J.1329.2019.03022

Qiao, N., and Yan, T.B. (2018). Effects of transcranial direct current stimulation on walking function in patients with early Parkinson's disease: a randomized controlled trial. Chin J. Phys. Med. Rehabil. 40, 509-512. doi: 10.3760/cma.j.issn.0254-1424.2018.07.007

Raja, M., and Bentivoglio, A. R. (2012). Impulsive and compulsive behaviors during dopamine replacement treatment in Parkinson's disease and other disorders. Curr. Drug Saf. 7, 63-75. doi: 10.2174/157488612800492726

Ransmayr, G. (2015). Cognitive impairment in Parkinson's disease. Psychiatr. Danub 27, 458-461. doi: 10.1093/med/9780199681648.003.0004

Ruggiero, F., Dini, M., Cortese, F., Vergari, M., Nigro, M., Poletti, B., et al. (2021). Anodal transcranial direct current stimulation over the cerebellum enhances sadness recognition in Parkinson's disease patients: a pilot study. Cerebellum. doi: 10.1007/s12311-021-01295-y

Schabrun, S. M., Lamont, R. M., and Brauer, S. G. (2016). Transcranial direct current stimulation to enhance dual-task gait training in Parkinson's disease: a pilot RCT. PLoS ONE 11:e0158497. doi: 10.1371/journal.pone.0158497

Shekhawat, G. S., Stinear, C. M., and Searchfield, G. D. (2013). Transcranial direct current stimulation intensity and duration effects on tinnitus suppression. Neurorehabil. Neural Repair 27, 164-172. doi: 10.1177/1545968312459908

Swank, C., Mehta, J., and Criminger, C. (2016). Transcranial direct current stimulation lessens dual task cost in people with Parkinson's disease. Neurosci. Lett. 626, 1-5. doi: 10.1016/j.neulet.2016.05.010

Tanaka, T., Takano, Y., Tanaka, S., Hironaka, N., Kobayashi, K., Hanakawa, T., et al. (2013). Transcranial direct-current stimulation increases extracellular dopamine levels in the rat striatum. Front. Syst. Neurosci. 7:6. doi: 10.3389/fnsys.2013.00006

Tremblay, S., Larochelle-Brunet, F., Lafleur, L. P., El Mouderrib, S., Lepage, J. F., and Theoret, H. (2016). Systematic assessment of duration and intensity of anodal transcranial direct current stimulation on primary motor cortex excitability. Eur. J. Neurosci. 44, 2184-2190. doi: 10.1111/ejn.1 3321

Voon, V., Fernagut, P.-O., Wickens, J., Baunez, C., Rodriguez, M., Pavon, N., et al. (2009). Chronic dopaminergic stimulation in Parkinson's disease: from dyskinesias to impulse control disorders.
Lancet Neurol. $\quad 8, \quad 1140-1149 . \quad$ doi: 10.1016/S1474-4422(09)70 287-X

Wu, D. C., and Wu, X. X. (2016). Effect of oral dopa hydrazine tablets combined with transcranial direct current stimulation on non-motor symptoms in Patients with Parkinson's disease. Shandong Pharmaceut. 56, 88-90. doi: 10.3969/j.issn.1002-266X.2016.31.029

$\mathrm{Wu}, \mathrm{S}$. P., and $\mathrm{Li}, \mathrm{X}$. (2020). The influence of transcranial direct current stimulation on rapid eye movement sleep disorders among persons with Parkinson's disease. Chin. J. Phys. Med. Rehabil. 42, 50-54. doi: 10.3760/cma.j.issn.0254-1424.2020.01.012

Yang, L. J., and He, X. Y. (2017). Analysis of curative effect of madopar combined with tDCS in the treatment of PD and effect on UPDRS score. J. Brain Neurol. Dis. 25, 661-664.

Yotnuengnit, P., Bhidayasiri, R., Donkhan, R., Chaluaysrimuang, J., and Piravej, K. (2018). Effects of transcranial direct current stimulation plus physical therapy on gait in patients with Parkinson's disease: a randomized controlled trial. Am. J. Phys. Med. Rehabil. 97, 7-15. doi: 10.1097/PHM.0000000000000783

Zhang, Z.-X., Roman, G. C., Hong, Z., Wu, C.-B., Qu, Q.-M., Huang, J.-B., et al. (2005). Parkinson's disease in China: prevalence in Beijing, Xian, and Shanghai. Lancet 365, 595-597. doi: 10.1016/S0140-6736(05)70801-1

Zhu, S. W. (2020). Clinical observation of transcranial direct current stimulation combined with Pramipexole in the treatment of Parkinson's disease. Tibetan Med. 41, 73-74.

Zintzaras, E., and Ioannidis, J. P. (2005). Heterogeneity testing in meta-analysis of genome searches. Genet Epidemiol. 28, 123-137. doi: 10.1002/gepi.20048

Conflict of Interest: The authors declare that the research was conducted in the absence of any commercial or financial relationships that could be construed as a potential conflict of interest.

Publisher's Note: All claims expressed in this article are solely those of the authors and do not necessarily represent those of their affiliated organizations, or those of the publisher, the editors and the reviewers. Any product that may be evaluated in this article, or claim that may be made by its manufacturer, is not guaranteed or endorsed by the publisher.

Copyright (C) 2021 Liu, Liu, Liu, Rao, Wang, Wang, Gong and Wen. This is an open-access article distributed under the terms of the Creative Commons Attribution License (CC BY). The use, distribution or reproduction in other forums is permitted, provided the original author(s) and the copyright owner(s) are credited and that the original publication in this journal is cited, in accordance with accepted academic practice. No use, distribution or reproduction is permitted which does not comply with these terms. 